\title{
Sequence and structural determinants of human APOBEC3H deaminase and anti-HIV-1 activities
}

\author{
Mithun Mitra ${ }^{1,6}$, Dustin Singer ${ }^{1}$, Yu Mano ${ }^{2}$, Jozef Hritz ${ }^{3,4,7}$, Gabriel Nam ${ }^{1}$, Robert J Gorelick ${ }^{5}$, In-Ja L Byeon ${ }^{3,4}$, \\ Angela M Gronenborn ${ }^{3,4}$, Yasumasa Iwatani ${ }^{2}$ and Judith G Levin ${ }^{1 *}$
}

\begin{abstract}
Background: Human APOBEC3H (A3H) belongs to the A3 family of host restriction factors, which are cytidine deaminases that catalyze conversion of deoxycytidine to deoxyuridine in single-stranded DNA. A3 proteins contain either one (A3A, A3C, A3H) or two (A3B, A3D, A3F, A3G) Zn-binding domains. A3H has seven haplotypes (I-VII) that exhibit diverse biological phenotypes and geographical distribution in the human population. Its single Zn-coordinating deaminase domain belongs to a phylogenetic cluster (Z3) that is different from the Z1- and Z2-type domains in other human A3 proteins. A3H Hapll, unlike A3A or A3C, has potent activity against HIV-1. Here, we sought to identify the determinants of $\mathrm{A} 3 \mathrm{H}$ Hapll deaminase and antiviral activities, using site-directed sequence- and structure-guided mutagenesis together with cell-based, biochemical, and HIV-1 infectivity assays.

Results: We have constructed a homology model of A3H Hapll, which is similar to the known structures of other A3 proteins. The model revealed a large cluster of basic residues (not present in A3A or A3C) that are likely to be involved in nucleic acid binding. Indeed, RNase A pretreatment of 293T cell lysates expressing A3H was shown to be required for detection of deaminase activity, indicating that interaction with cellular RNAs inhibits A3H catalytic function. Similar observations have been made with A3G. Analysis of A3H deaminase substrate specificity demonstrated that a $5^{\prime} \mathrm{T}$ adjacent to the catalytic $\mathrm{C}$ is preferred. Changing the putative nucleic acid binding residues identified by the model resulted in reduction or abrogation of enzymatic activity, while substituting Z3-specific residues in $\mathrm{A} 3 \mathrm{H}$ to the corresponding residues in other $\mathrm{A} 3$ proteins did not affect enzyme function. As shown for A3G and A3F, some A3H mutants were defective in catalysis, but retained antiviral activity against HIV-1 vif (-) virions. Furthermore, endogenous reverse transcription assays demonstrated that the E56A catalytic mutant inhibits HIV-1 DNA synthesis, although not as efficiently as wild type.
\end{abstract}

Conclusions: The molecular and biological activities of $\mathrm{A} 3 \mathrm{H}$ are more similar to those of the double-domain A3 proteins than to those of A3A or A3C. Importantly, A3H appears to use both deaminase-dependent and -independent mechanisms to target reverse transcription and restrict HIV-1 replication.

Keywords: HIV-1, APOBEC3H, Homology model, Deaminase activity, Antiviral activity, Deaminase-independent restriction, Reverse transcription

\section{Background}

The human APOBEC3 (A3) family consists of seven cytidine deaminases that catalyze the conversion of deoxycytidine $(\mathrm{dC})$ to deoxyuridine $(\mathrm{dU})$ in single-stranded (ss) DNA, thereby inducing G-to-A hypermutation in doublestranded DNA [1-5]. A3 proteins play an important role

\footnotetext{
* Correspondence: levinju@mail.nih.gov

'Section on Viral Gene Regulation, Program in Genomics of Differentiation, Eunice Kennedy Shriver National Institute of Child Health and Human Development, National Institutes of Health, Bethesda, MD 20892-2780, USA Full list of author information is available at the end of the article
}

in the innate immune defense system by inhibiting a broad range of exogenous viruses such as human immunodeficiency virus type 1 (HIV-1) (reviewed in refs. [6-13]), human T-lymphotropic virus type 1 (HTLV-1) $[14,15]$, and hepatitis B virus (HBV) $[16,17]$ as well as endogenous retrotransposons such as LINE-1 and Alu elements (reviewed in refs. $[7,18])$. These proteins contain either one $(\mathrm{A} 3 \mathrm{~A}, \mathrm{~A} 3 \mathrm{C}$, and $\mathrm{A} 3 \mathrm{H})$ or two $(\mathrm{A} 3 \mathrm{~B}$, A3D (formerly known as A3D/E), A3F, and A3G) Znbinding domains with the conserved motif $\mathrm{HX}_{1} \mathbf{E X}_{23-24}$ $\mathrm{CX}_{2-4} \mathrm{C}$ (X is any amino acid) [19] (reviewed in refs. 
$[20,21])$. The histidine and two cysteines coordinate a $\mathrm{Zn}$ ion, while the glutamic acid residue is thought to act as a proton shuttle during catalysis [6,22]. Based on phylogenetic analysis, the Zn-binding domains were further classified into the following groups: Z1 (A3A and $\mathrm{C}$-terminal domains (CTD) of $\mathrm{A} 3 \mathrm{~B}$ and $\mathrm{A} 3 \mathrm{G}), \mathrm{Z2}$ (A3C, N-terminal domains (NTD) of A3B and A3G, and both NTD and CTD of A3D and A3F), and Z3 (A3H) [23,24].

$\mathrm{A} 3 \mathrm{H}$ is the most divergent member of the A3 family and has a single $\mathrm{Zn}$-binding domain that belongs to the unique $\mathrm{Z} 3$ group $[24,25]$. The $\mathrm{A} 3 \mathrm{H}$ message undergoes alternative splicing to generate variants containing distinct C-terminal regions [26,27]. Furthermore, unlike other $A 3$ genes, $A 3 H$ is present in the human population as different haplotypes containing functional polymorphisms. At present, seven haplotypes of $\mathrm{A} 3 \mathrm{H}$ (Hap I-VII) have been identified that differ in their antiviral activities: only Hap II, Hap V, and Hap VII are stably expressed and are able to restrict Vif-deficient HIV-1 [26-29]. Interestingly, the distribution of $\mathrm{A} 3 \mathrm{H}$ haplotypes in the human population is correlated with geographical location [26,29]. For example, a higher frequency of HapII is present in Africa, compared to Europe and Asia, possibly due to a greater selection pressure against pathogens endogenous to that region [26].

HIV-1 Vif, which counteracts antiviral activity by promoting proteasomal degradation of $\mathrm{A} 3 \mathrm{C}, \mathrm{A} 3 \mathrm{D}, \mathrm{A} 3 \mathrm{~F}$, and A3G, exhibits different degrees of potency against the individual $\mathrm{A} 3 \mathrm{H}$ haplotypes [12,29-32]. In cell-based assays, the sensitivity of antiviral A3H HapII towards Vif was shown to be dependent upon the Vif subtype $[33,34]$ and a remarkable study involving recently infected HIV-1 patients revealed adaptive changes in viral Vif sequences that were attributed to the presence of the different antiviral $\mathrm{A} 3 \mathrm{H}$ haplotypes [32]. These observations provide strong evidence for a significant role of $\mathrm{A} 3 \mathrm{H}$ as an antiviral defense protein.

A3 proteins deaminate $\mathrm{dC}$ residues in a sequencespecific manner. For example, A3A exhibits a greater preference for the $\mathrm{dC}$ in the center of a TCA target [35-42], while A3G specifically deaminates the $\mathrm{dC}$ in a CCC motif [21,43-45]. Evaluation of the structural basis of the sequence specificity suggested that it is determined by the architecture of the active site and surrounding amino acids, in particular, residues in loop 7 [41-46] (reviewed in refs. [21,47]). Although, $\mathrm{A} 3 \mathrm{H}$ is known to deaminate $\mathrm{dC}$ in TC motifs of HIV-1 minusstrand DNA $[27,48]$, a detailed investigation of the nucleotide context immediately $5^{\prime}$ and $3^{\prime}$ of the $\mathrm{dC}$ on sequence-specific deamination has not been reported. In addition, the amino acid residues that are important for $\mathrm{A} 3 \mathrm{H}$ deaminase activity and the role of structure in dictating biological function have not been investigated.
In the present study, we focus on the biochemical and structural determinants of $\mathrm{A} 3 \mathrm{H}$ HapII (to be referred to as "A3H") deaminase and antiviral activities, using sitedirected and structure-guided mutagenesis. We have constructed a homology model of $\mathrm{A} 3 \mathrm{H}$ and find that the $\mathrm{A} 3 \mathrm{H}$ structure, as expected, is similar to the known structures of A3A [41], A3C [49], A3G-CTD [43,50-53], and A3F-CTD [54,55], with differences mainly in flexible loop regions. Our model resembles the ones generated by (i) MODELLER [56], based on the A2 and A3G-CTD structures [57], and (ii) the automated structure-homologymodeling server, SWISS-MODEL, using the A2 structure [13], although details may be different. Interestingly, our model also reveals a large cluster of basic residues, which is not present in other A3 deaminase-active domains, and is consistent with the observation that deaminase activity in cell-free extracts is detected only after removal of RNA by treatment with RNase A. In addition, we have evaluated the deaminase and antiviral activities of a series of $\mathrm{A} 3 \mathrm{H}$ mutants. Although these activities can be correlated in most cases, a significant number of mutants lacking enzymatic activity are still able to inhibit HIV-1 replication, albeit at a lower efficiency than wild type (WT). This result raises the possibility that $\mathrm{A} 3 \mathrm{H}$ restricts $\mathrm{HIV}-1$ by catalytic-dependent and -independent mechanisms. Indeed, assays of endogenous reverse transcription (ERT) support this hypothesis. Taken together, our findings provide new insights into the role of $\mathrm{A} 3 \mathrm{H}$ as a naturally occurring human restriction factor and should contribute to continuing efforts to combat HIV infection in the African human population.

\section{Results}

Sequence- and structure-based design of $\mathrm{A} 3 \mathrm{H}$ mutants

In this work, we set out to investigate the determinants of $\mathrm{A} 3 \mathrm{H}$ cytidine deaminase and antiviral activities, using a mutagenic approach. Given A3H's unique Z3-type Znbinding domain [24], we initially carried out a sequence comparison of the $\mathrm{Z} 3$ domain of $\mathrm{A} 3 \mathrm{H}$ with the $\mathrm{Z} 1$ and $\mathrm{Z} 2$ domains of other A3 proteins to identify conserved and distinct regions in $\mathrm{A} 3 \mathrm{H}$ (Additional file 1: Figure S1). Sequence identities range from $28-43 \%$ and the $\mathrm{Z} 3$ domain shares the greatest identity with the $\mathrm{Z} 2$ domains of A3C and A3F-CTD and the least with A3D-NTD. The sequence alignment also identified four residues unique to the Z3 domain: T81, L102, S109, and V135, which are replaced by $\mathrm{S}, \mathrm{V}, \mathrm{A}$, and I in other Z domains.

A more extensive sequence alignment was performed by comparing the residues in the complete $\mathrm{A} 3 \mathrm{H}$ protein with the sequences of A3 proteins whose three-dimensional structures have been solved at high resolution, i.e., A3A [41], A3C [49], A3F-CTD [54,55] and A3G-CTD [43,50-53] (Figure 1). The overall sequence identity between $\mathrm{A} 3 \mathrm{H}$ and each of these proteins is very similar and 


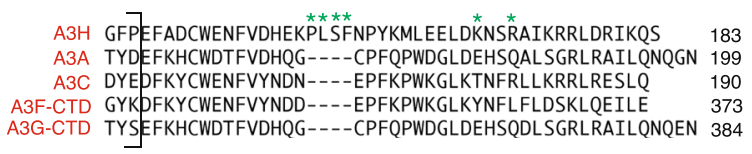

Figure 1 Sequence alignment of $\mathrm{A} 3 \mathrm{H}$ Hapll (residues 1 to 183) and four $\mathrm{A} 3$ deaminase-active proteins whose structures have been solved: A3A (1 to 199) [41], A3C (1 to 190) [49], A3F-CTD (185-373) [54,55], and A3G-CTD (191-384) [53] (also see refs. [43,50-52]). The $\mathrm{A} 3 \mathrm{H}$ residues mutated in this study are highlighted with green asterisks and the active site residues are highlighted in blue. The region inside the square brackets represents the $Z$ domain sequences for all of the proteins. The amino acids that comprise A3H loop 7 are also shown. The sequence alignment was generated using Lasergene software (DNASTAR, Inc., Madison, WI, USA).

ranges from 35 to $38 \%$ (Table 1). The $\mathrm{Z}$ domains (bracketed) include the loop 7 residues, a region that is involved in deaminase substrate specificity [41-46] (reviewed in $[21,47])$. Interestingly, loop 7 sequences for different A3 proteins display alternative arrangements of polar and non-polar residues. For example, A3H contains a stretch of aromatic residues (YYHW, 112-115), while in A3GCTD, the corresponding residues are polar (YDDQ, 315318). In addition, a unique stretch of residues was noted outside the $\mathrm{Z}$ domains, namely 154-157 (PLSF), which is absent in the other $\mathrm{A} 3$ proteins.

To probe the role of $\mathrm{A} 3 \mathrm{H}$ residues in enzymatic activity in relation to their location in the structure, we constructed a homology model based on the X-ray structure of A3G-CTD [53] (Figure 2A). Comparison of our A3H model with A3G-CTD (PDB: 3IR2) [53], A3A (PDB: 2 M65) [41], A3C (PDB: 3 VOW) [49], and A3F-CTD (PDB: 4IOU) [54] showed that the A3H model is similar to the other A3 structures, which have r.m.s.d. values ranging from 3.1 to $3.5 \AA$. The major differences between the

Table 1 Sequence comparison of $\mathrm{A} 3 \mathrm{H}$ with other deaminase-active $A 3$ proteins and theoretical isoelectric points (pl)

\begin{tabular}{llll}
\hline & $\begin{array}{l}\text { Zinc-binding } \\
\text { domain (Z) } \\
\text { type }\end{array}$ & $\begin{array}{l}\text { \% Sequence } \\
\text { identity to } \\
\text { A3H }^{\mathbf{a}}\end{array}$ & Theoretical $\mathbf{~}^{\mathbf{b}}$ \\
\hline A3A (1-199) & $Z 1$ & 36 & 6.3 \\
A3C (1-190) & $Z 2$ & 38 & 7.5 \\
A3F-CD2 (185-373) & $Z 2$ & 36 & 5.0 \\
A3G-CD2 (191-384) & Z1 & 35 & 6.2 \\
A3H Hapll (1-183) & Z3 & 100 & 8.9
\end{tabular}

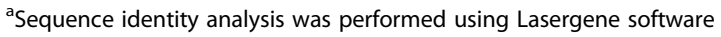
(DNASTAR, Inc.).

${ }^{\mathrm{b}}$ The theoretical pl values were calculated using the Protparam online web-based program (http://web.expasy.org/compute_pi/). various A3 structures occur in the loops, as suggested previously [41] (Additional file 2: Figure S2).

Comparisons of the electrostatic surface features of A3H (Figure 2B, Additional file 3: Figure S3) and other A3 proteins (A3G-CTD, A3A, A3C, and A3F-CTD) (Additional file 3: Figure S3) reveal a striking difference in the clustering of basic residues (blue regions), consistent with the fact that $\mathrm{A} 3 \mathrm{H}$ is highly basic (theoretical pI, 8.9) compared to the other single-domain A3 proteins A3A (pI, 6.3) and A3C (pI, 7.5) (Table 1). Indeed, the basic character of $\mathrm{A} 3 \mathrm{H}$ is more similar to the positively charged N-terminal domains (NTDs) of the double-domain proteins, A3F (residues 1-180; pI, 8.6) and A3G (residues 1-185; pI, 9.4). The NTDs of A3F and A3G play an important role in binding viral RNA that is packaged; however, they are enzymatically inactive [58-61]. Since A3H is a single-domain protein, it is likely that the basic residues serve a dual function, i.e., binding both viral and/or cellular RNA as well as interacting with the ssDNA substrate for deamination.

\section{RNA inhibits the deaminase activity of $\mathrm{A} 3 \mathrm{H}$}

Deaminase activity of $\mathrm{A} 3 \mathrm{H}$ variants was tested in $293 \mathrm{~T}$ cell lysates using a TTCA-containing 40-nt oligonucleotide as described in Methods; protein expression was monitored by Western blot analysis, using an $\mathrm{A} 3 \mathrm{H}-$ specific antibody probe (Figure 3A). We selected the TTCA motif, since analysis of HIV-1 viral DNA showed that the $\mathrm{dC}$ residue in TC motifs was preferentially deaminated by A3H $[27,32,48,62]$. Surprisingly, we observed only trace amounts of deaminase activity in (WT) $\mathrm{A} 3 \mathrm{H}$ cell lysates (Figure $3 \mathrm{~B}$ and $\mathrm{C}$ ). However, activity was clearly detectable after treating these lysates with RNase A, while no effect was seen with cells transfected with the empty vector control. These results suggest that $\mathrm{A} 3 \mathrm{H}$ is 

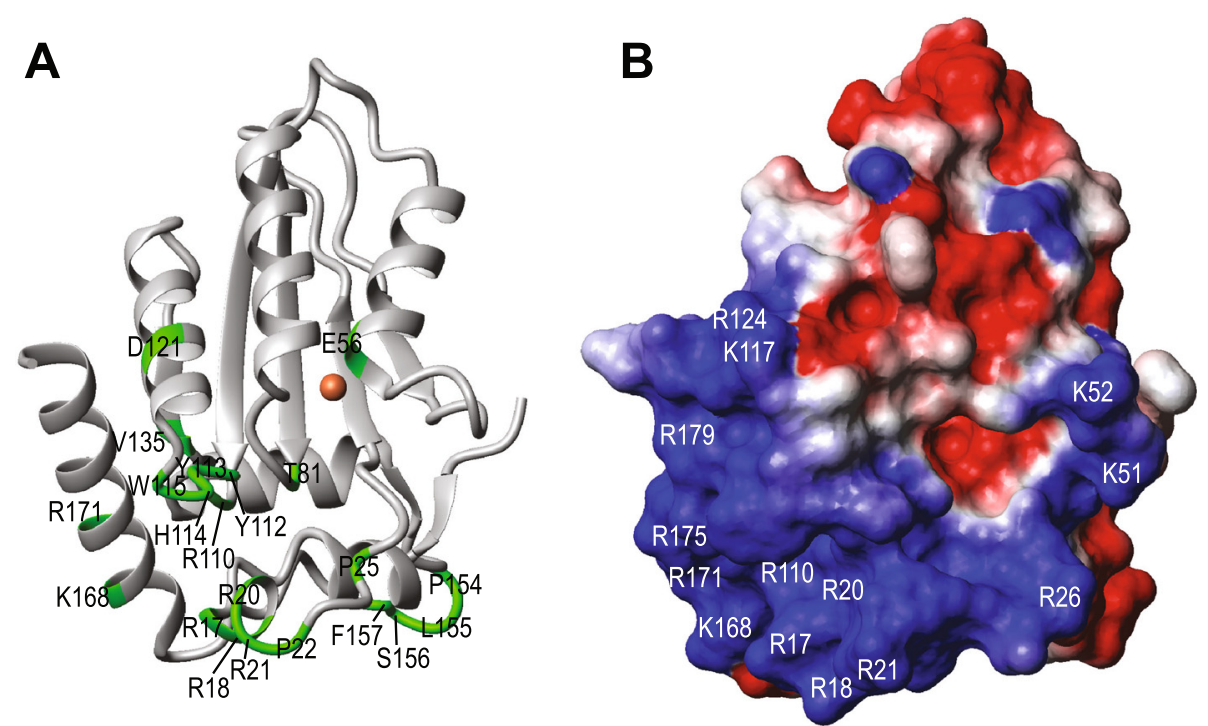

Figure $2 \mathbf{A} \mathbf{A} \mathbf{H}$ model structure. (A) Ribbon representation of the $\mathrm{A} 3 \mathrm{H}$ model showing the positions of residues mutated in this study in green. The $\mathrm{Zn}$ ion is colored in brown. (B) Electrostatic map of the $\mathrm{A} 3 \mathrm{H}$ model depicting regions with positive (blue) and negative (red) electrostatic potentials. Basic residues are shown in white.

bound to RNA present inside the cell and that this interaction with RNA inhibits $\mathrm{A} 3 \mathrm{H}$ deaminase activity, presumably in a competitive manner. Interestingly, a similar inhibitory effect on enzyme function was also observed with A3G $[7,63]$.

\section{Deaminase target specificity of $\mathrm{A} 3 \mathrm{H}$}

Until now, detailed analysis of A3H deaminase specificity has not been reported. We therefore performed deaminase assays using oligonucleotides containing different motifs: TTCA, TTCT, TTCG, TGCA, and ACCCA, where either a purine $(\mathrm{G}$ ) or a pyrimidine ( $\mathrm{T}$ or $\mathrm{C}$ ) is present at the position immediately $5^{\prime}$ of the target $\mathrm{dC}$ residue. As shown in Figure 3D, the presence of a $5^{\prime} \mathrm{T}$ (e.g., TTCA, TTCT, and TTCG) yielded the highest amounts of deamination product ( $\sim 90 \%$ substrate conversion with $5 \mu \mathrm{g}$ of total protein after incubation for $1 \mathrm{~h}$ at $\left.37^{\circ} \mathrm{C}\right)$, while a $5^{\prime} \mathrm{G}$, as in TGCA, was poorly tolerated ( 17\%). The rank order of deamination efficiency of the substrates is: TTCA TTCT $\sim$ TTCG > ACCCA > TGCA. These data suggest a less stringent requirement for the 3 ' position, where either a purine or a pyrimidine is tolerated, since similar levels of deamination product were formed with substrates containing TTCA, TTCT, and TTCG motifs. (Note that some difference in the deamination efficiency of substrates with TTCA, TTCT, and TTCG motifs might occur if less than $1 \mu \mathrm{g}$ of lysate were added to the reaction.)

\section{Identification of $\mathrm{A} 3 \mathrm{H}$ residues important for deaminase activity}

The sequence-structure analysis (Figures 1 and 2) provided a rationale for mutagenesis of $\mathrm{A} 3 \mathrm{H}$ residues that could potentially play a role in catalytic activity. Deaminase and HIV-1 infectivity assays of WT and mutant constructs were performed in parallel to evaluate enzymatic (Figure 4) and antiviral (Figure 5) activities. The data in Figure 4A and D are arranged according to residue position along the polypeptide chain from the $\mathrm{N}$ - to $\mathrm{C}$-terminus. As expected, the active site mutant E56A (negative control) did not display any deaminase activity (Figure 4B).

In our initial screen, we focused on residues that are Z3-specific (Additional file 1: Figure S1), in order to probe whether these residues were selected throughout evolution to ensure $\mathrm{A} 3 \mathrm{H}$ enzymatic activity. We chose two examples from this group, T81 and V135, which correspond to $\mathrm{S}$ and $\mathrm{I}$, respectively, in $\mathrm{Z} 1$ and $\mathrm{Z} 2 \mathrm{Zn}$-binding domains (Figure 1). Mutants with these Z1-Z2 substitutions were expressed at levels comparable to or higher than WT (Figure 4A and D). Interestingly, changing T81 to $S$ did not reduce deaminase activity, whereas the T81 to A mutation completely abolished activity (Figure 4B). Note that the mutant protein T81A was expressed at levels comparable to WT (Figure 4A). Since both threonine and serine possess a hydroxyl group, while alanine does not, this may suggest that the side chain of T81 is involved in a polar interaction. Changing the analogous residue $\mathrm{S} 97$ in A3A (Z1 type) to $\mathrm{T}$ did not affect deaminase activity (Figure 4B), consistent with retention of the important hydroxyl group. Similarly, mutating V135 to I also represents a conservative change and not surprisingly, there was no effect on enzymatic activity (Figure 4E).

In contrast, deletion of the unique stretch of amino acids, PLSF (aa 154-157), which contains three bulky hydrophobic residues, proline, leucine, and phenylalanine, 

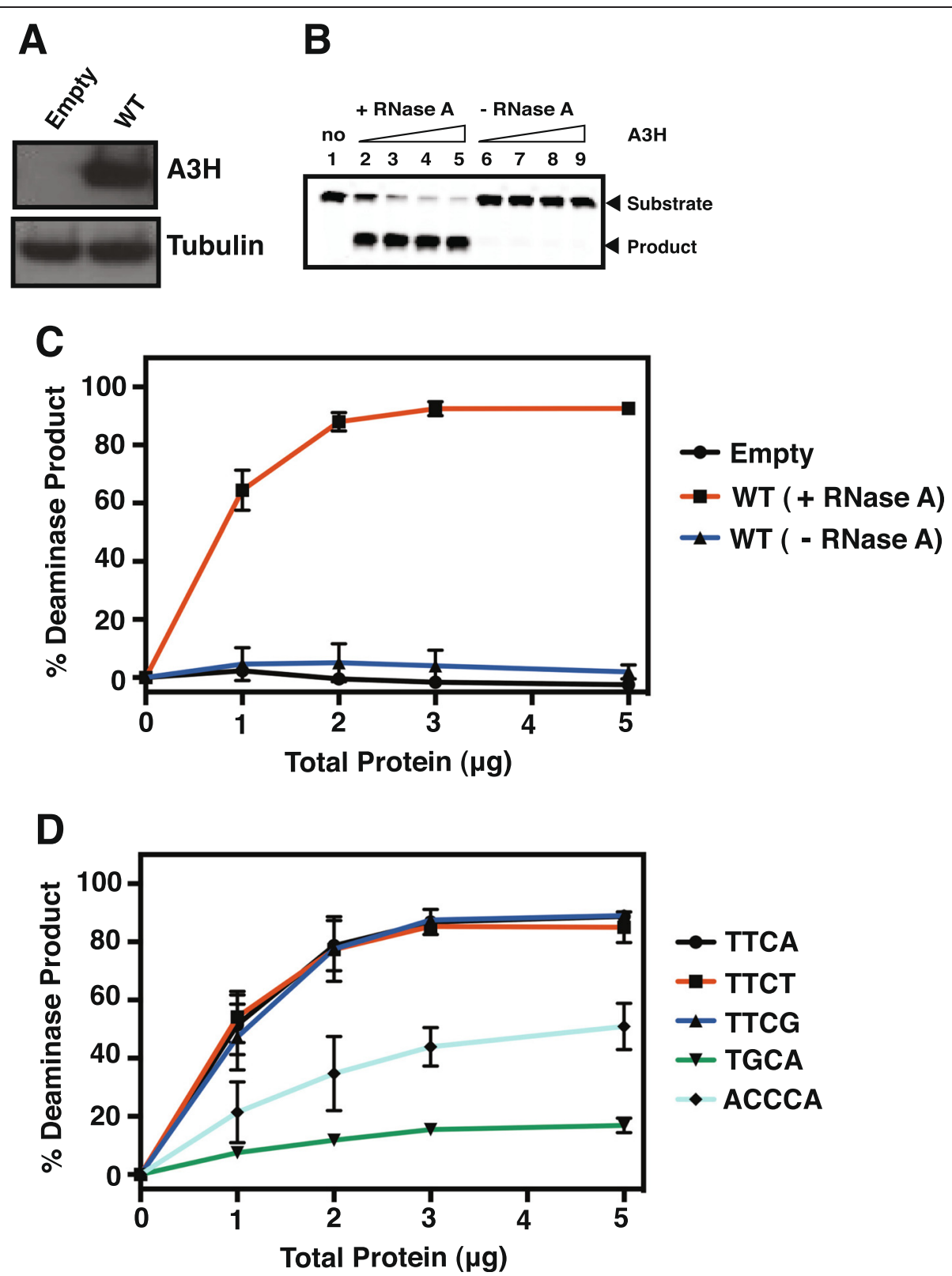

Figure $3 \mathrm{~A} 3 \mathrm{H}$ deaminase activity dependence on RNase A treatment of extracts and substrate specificity. (A) Western blot analysis showing the WT A3H protein levels in 293T cells. Transfection of the empty vector (no A3H) served as a negative control and showed that 293T cells do not contain detectable levels of endogenous $\mathrm{A} 3 \mathrm{H}$. The tubulin loading control is also shown. (B) Representative gel illustrating assay of WT A3H deaminase activity in a cell extract using a 40-nt TTCA-containing oligonucleotide substrate. The oligonucleotide was incubated with increasing amounts of $\mathrm{A} 3 \mathrm{H}$ extract in the presence and absence of RNase A. The positions of the substrate ( $40 \mathrm{nt}$ ) and the deamination product are indicated by arrows to the right of the gel. Lane 1, empty vector control; lanes 2 and 6, lanes 3 and 7, lanes 4 and 8, and lanes 5 and 9 represent reactions containing $1 \mu \mathrm{g}, 2 \mu \mathrm{g}, 3 \mu \mathrm{g}$, and $5 \mu \mathrm{g}$ of total protein, respectively. (C) The percent (\%) deamination product was calculated as described in Methods and was plotted against the amounts of total protein. (D) Deaminase assay using WT A3H extract and 40-nt oligonucelotides containing the following deaminase motifs: TTCA, TTCT, TTCG, TGCA, and ACCCA. The data were analyzed and plotted as described in (C).

reduced enzymatic activity to background level (Figure 4E). This suggests that a major conformational change was introduced by the deletion, causing an overall structural defect. In turn, this would lead to destabilization of the protein, which could explain the low protein expression level of this mutant (Figure 4D) and inability to be packaged efficiently (see below) (Figure 5A). Changing another unique $\mathrm{A} 3 \mathrm{H}$ residue, $\mathrm{P} 25$ to $\mathrm{R}$, abrogated $\mathrm{A} 3 \mathrm{H}$ deaminase activity (Figure 4B), although its expression level was normal (Figure 4A).

Basic residues in A3 proteins are often involved in specific and non-specific nucleic acid interactions $[21,47,64]$. 

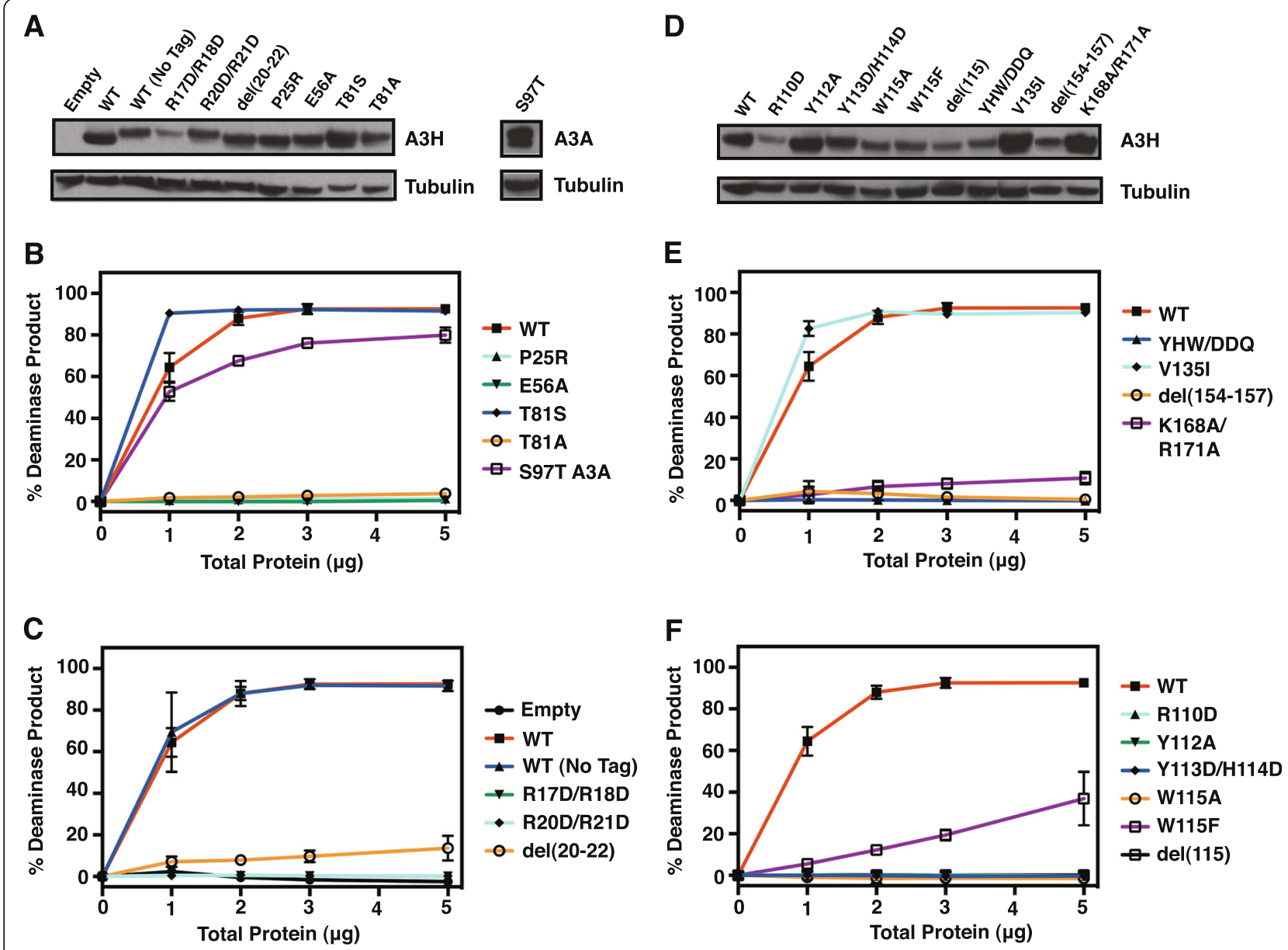

Figure 4 Deaminase activities of A3H WT and mutants. (A) and (D) Western blot analysis showing the amounts of A3H WT and mutants and A3A S97T in 293T cells. (B, C, E, F) Deaminase assays using 293T cell extracts expressing A3H WT and mutants and A3A S97T. The deaminase assays were performed as described in Methods.

To examine the role of these residues in $\mathrm{A} 3 \mathrm{H}$ deaminase activity (Figure $4 \mathrm{C}$ and F) and to determine whether the location of these residues in the $\mathrm{A} 3 \mathrm{H}$ model structure is related to their function, we focused on residues in the "basic patch" (Figure 2B): R17, R18, R20, R21, R110, K168, and R171. Note that R18, R20, and R21 are not present in other A3 proteins (Figure 1). We constructed a single mutant with an $\mathrm{R} \rightarrow \mathrm{D}$ change (R110D) as well as double mutants R17D/R18D, R20D/R21D, and K168A/R171A. With the exception of R17D/R18D and R110D, the mutant proteins were efficiently expressed (Figure 4A and D), but almost all lacked deaminase activity (Figure 4C, 4E, and F), even at high amounts of total protein. Two mutants, del (20-22) (Figure 4C) and K168A/R171A (Figure 4E), displayed greatly reduced, but measurable activity $(\sim 15 \%$ and $\sim 11 \%$ product, respectively, at $5 \mu \mathrm{g}$ total protein). These results suggest that positive charges are necessary for binding of $\mathrm{A} 3 \mathrm{H}$ to the ssDNA substrates and that the introduction of a single negative charge in the basic patch disrupts the favorable charge-charge interaction. The change to the non-polar alanine or deletion of residues $20-22$, which are present only in $\mathrm{A} 3 \mathrm{H}$ as a unique insertion, is less detrimental. Taking all of the above data together, it appears likely that these basic residues form part of the $\mathrm{A} 3 \mathrm{H}$ nucleic acid binding interface.

Another region of interest, loop 7 (Figure 1), which in other A3 proteins has been shown to be important for substrate binding and recognition [41-46] (reviewed in refs. [21,47]) was also subjected to mutagenesis. Several of the mutant proteins e.g., W115A, W115F, del(115), and Y113D/H114D/ W115Q (YHW/DDQ) were expressed at low levels compared to WT A3H (Figure 4D), possibly resulting from reduced protein stability due to removal of the large tryptophan side chain. Changing residues Y112, Y113, and H114, e.g., Y112A, Y113D/H114D (Figure 4F), and YHW/DDQ, which introduces polar residues from the A3G-CTD loop 7 (Figure 4E), led to the complete loss of deaminase activity. A similar result was obtained when W115 was deleted (del115) or changed to 

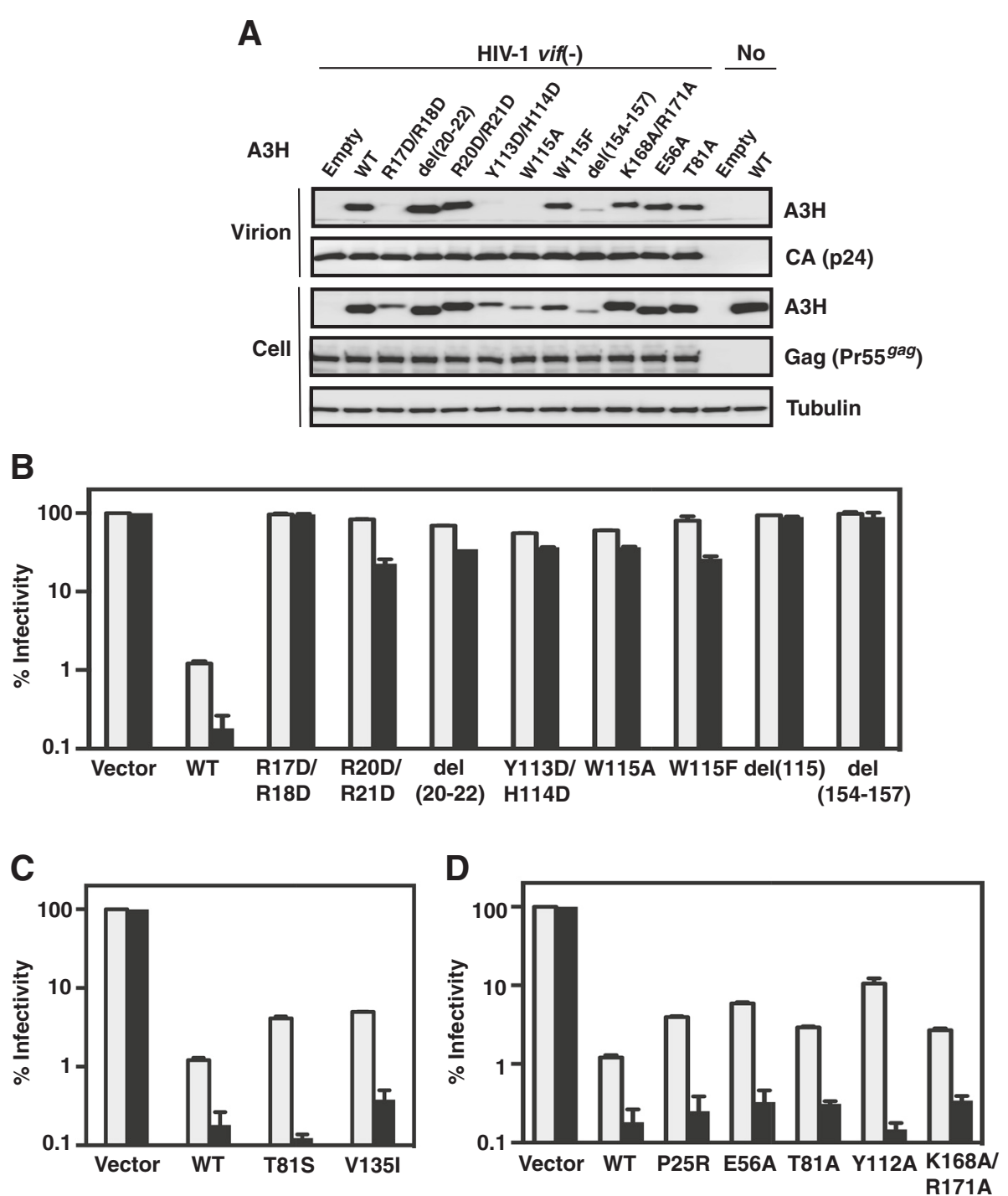

Figure 5 Antiviral activities of A3H WT and mutants. (A) Western blot analysis showing the amounts of A3H WT and mutants in HIV-1 vif (-) virions and 293T cells. 293T cells were transfected with HIV-1vif (-) and A3H WT or mutant plasmids at a 1:1 ratio $(1 \mu \mathrm{g}$ each for determination of expression in cell extracts and $8 \mu \mathrm{g}$ each for determination of $\mathrm{A3H}$ in viral lysates). Cell extracts (10 $\mu \mathrm{g}$ of total protein) as well as viral lysates ( $8 \mu \mathrm{l}$ of viral pellet resuspended in $200 \mu \mathrm{l}$ of loading buffer) were subjected to Western blot analysis. Viral lysates were probed with antibodies to the N-terminal FLAG tag of A3H and HIV-1 CA; cell extracts were probed with antibodies to the N-terminal FLAG tag of A3H, HIV-1 Gag (Pr55 ${ }^{\text {gag }}$ ), and tubulin. Controls: Left side, EMPTY refers to HIV-1vif (-) and empty vector (pTR600); Right side, EMPTY refers to empty vector alone; WT, refers to A3H plasmid DNA alone. (B-D) Antiviral activity was determined as described in Methods. The gray and black bars respresent transfection with $0.1 \mathrm{\mu g}$ or $1 \mu \mathrm{g}$ of the indicated $\mathrm{A} 3 \mathrm{H}$ plasmid, respectively.

alanine (W115A) (Figure 4F). However, changing tryptophan to another aromatic residue, phenylalanine (W115F) (Figure 4F), led to only partial loss of deaminase activity, suggesting that these aromatic residues could be involved in base stacking interactions with the nucleic acids. Finally, we tested the deaminase activity of W115A, del115, Y113D/H114D, YHW/DDQ, and R110D at $10 \mu \mathrm{g}$ total protein, but again, no activity was observed (data not shown). Collectively, these results suggest that the residues in $\mathrm{A} 3 \mathrm{H}$ loop 7 are also likely to participate in specific interactions with nucleic acids.

\section{Role of $\mathrm{A} 3 \mathrm{H}$ residues in $\mathrm{A} 3 \mathrm{H}$ antiviral activity}

Inhibition of HIV-1vif (-) replication by A3F and A3G is mediated by both deaminase-dependent and -independent mechanisms $[20,61,65-79]$. In an early study, it was concluded that $\mathrm{A} 3 \mathrm{H}$ antiviral activity is deaminase-independent [80], but other reports indicated that this activity is dependent on catalysis $[25,27]$. It was therefore of interest to evaluate whether the presence or absence of deaminase activity (Figure 4) could be correlated with $\mathrm{A} 3 \mathrm{H}$ antiviral activity (Figure 5) in our system.

To determine whether the inability of certain mutants to restrict HIV-1 replication was due to a defect 
in $\mathrm{A} 3 \mathrm{H}$ packaging, Western blot analysis was performed (Figure 5A). Virions were probed for capsid protein (CA) as well as for $\mathrm{A} 3 \mathrm{H}$. For comparison, expression levels of $\mathrm{A} 3 \mathrm{H}$ and tubulin in cells were also measured and the data were similar to the results in Figure 4A and D. Interestingly, several mutants that were expressed poorly in cells, packaged little or no $\mathrm{A} 3 \mathrm{H}$ in virions (Figure 5A). These mutants include: R17D/R18D, Y113D/H114D, W115A, and del(154-157). Although W115F exhibited lower levels of protein than WT (Figures 4D and Figure 5A), a significant amount of $\mathrm{A} 3 \mathrm{H}$ was encapsulated (Figure 5A).

Single-cycle infectivity assays of virions produced in cells expressing WT and mutant A3H proteins were performed using two different amounts of $\mathrm{A} 3 \mathrm{H}$ plasmid $(0.1 \mu \mathrm{g}$ and $1 \mu \mathrm{g})$. Under conditions where the $0.1 \mu \mathrm{g}$ dose was used, the antiviral activities of the mutants could be divided into three groups: (1) mutants that showed little or no deaminase or antiviral activities (i.e., having values similar to the empty vector control), such as R17D/R18D, R20D/R21D, del(20-22) (low level of deaminase activity), Y113D/H114D, W115A, W115F (reduced level of deaminase activity), del(115), and del (154-157) (Figure 5B); (2) mutants with WT levels of deaminase activity and appreciable antiviral activity, albeit lower than that of WT, such as T81S and V135I (Figure 5C); and (3) mutants completely lacking (P25R, E56A, T81A, Y112A) or having reduced levels (K168A/ R171A) of deaminase activity that retain antiviral activity (Figure 5D).

The results obtained with mutants in groups 1 and 2 are consistent with deaminase-dependent antiviral activity, since group 1 mutants have neither activity and group 2 mutants have both. With the exception of R20D/R21D, del (20-22), and W115F, all of the group 1 mutants that were analyzed by Western blot exhibited packaging defects (see above), which would account for their lack of virion-associated deaminase and anti-HIV activities. Interestingly, the results with group 3 mutants were discordant and suggest that $\mathrm{A} 3 \mathrm{H}$ may also utilize a deaminaseindependent mechanism for HIV-1 restriction. Note that the levels of antiviral activity for these deaminase-negative mutants were still lower than WT values $(0.1 \mu \mathrm{g}$ condition), suggesting that deaminase activity is indeed required for maximal activity.

The antiviral activities of WT and a majority of the mutants increased upon increasing the transfected plasmid amount to $1 \mu \mathrm{g}$. Surprisingly, the antiviral activities of T81S and Y112A were similar to WT levels under this condition. The behavior of Y112A in our study differed from that of A3H Hap VII Y112A, which although expressed efficiently in cells, was poorly packaged and exhibited a very low level of anti-HIV-1 activity [29]. The explanation for this difference is not clear. We also performed a side-by-side comparison of the activities of the deaminase-negative catalytic mutants of A3G (E259Q) and A3H (E56A) as well as the respective WTs (Additional file 4: Figure S4) and found that both $\mathrm{A} 3 \mathrm{H}$ and A3G WT and mutant samples displayed dosedependent inhibition of HIV-1 infectivity. This suggests that A3G and $\mathrm{A} 3 \mathrm{H}$ utilize a common mechanism for antiviral activity.

\section{Mechanism of $\mathrm{A} 3 \mathrm{H}$ antiviral activity}

A3G and A3F deaminase-independent anti-viral activity targets nascent DNA synthesis during reverse transcription [20,68-79]. To determine whether $\mathrm{A} 3 \mathrm{H}$ deaminase-independent inhibition of HIV-1 infectivity is also associated with a reduction in viral DNA synthesis, we performed ERT assays using WT A3H and the active site mutant E56A.

In our assays, HIV-1vif (-) and $\mathrm{A} 3 \mathrm{H}$ plasmids were transfected at two different ratios: 10:1 or 3:1, respectively (see Methods). Synthesis of R-U5 DNA (minus-strand strong-stop DNA) and R-5'UTR DNA (plus-strand DNA synthesized after plus-strand transfer) was measured over a 4-h time interval (Figure 6A and B). With WT A3H using the 10:1 condition, the levels of R-U5 were decreased to about $40 \%$ of the minus $\mathrm{A} 3 \mathrm{H}$ control (100\%) at $2 \mathrm{~h}$ (Figure 6A). The levels were drastically reduced for WT (3:1 condition) ( 15\% at $2 \mathrm{~h})$ and the time course showed no appreciable change in level over the 4-h window. The E56A mutant, which lacks deaminase activity, was also capable of reducing the R-U5 levels to about $60 \%$ at $2 \mathrm{~h}$ (10:1 condition). At the higher dose (3:1 condition), R-U5 levels were further reduced relative to the control $(\sim 25 \%$ at $2 \mathrm{~h})$, but the inhibition did not saturate even after $4 \mathrm{~h}$, indicating partial inhibition. Similar trends for the WT and E56A mutant were also observed when synthesis of R-5'UTR (plus-strand synthesis) was monitored (Figure 6B). These results demonstrate that $\mathrm{A} 3 \mathrm{H}$ deaminase-independent HIV-1 restriction involves inhibition of viral DNA synthesis.

\section{Discussion}

In this work, we use sequence- and structure-guided mutagenesis to provide a detailed analysis of $\mathrm{A} 3 \mathrm{H}$ deaminase activity and to correlate enzymatic function with antiviral activity. In addition, we identify the A3H structural elements associated with these activities. We also show that $\mathrm{A} 3 \mathrm{H}$ deaminase activity in cell extracts is suppressed by binding to cellular RNAs (Figure 3), consistent with an earlier report indicating that $\mathrm{A} 3 \mathrm{H}$ interacts strongly with 7SL, Y1, Y3, and Y4 RNAs in 293T cells [57]. Interestingly, extensive mutagenesis studies demonstrate that the determinants of deaminase and antiviral activities are not necessarily the same, as a number of deaminase-negative mutants retain antiviral activity (Figures 4 and 5). Thus, $\mathrm{A} 3 \mathrm{H}$ appears to inhibit HIV-1 


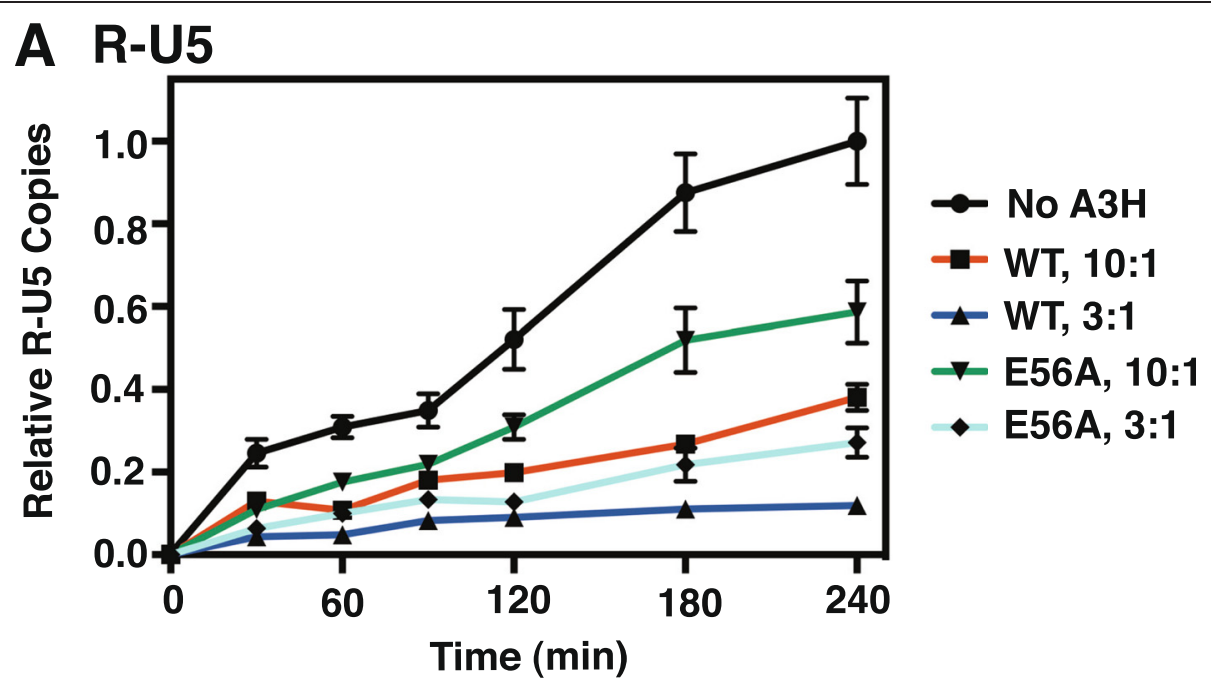

B R-5'UTR

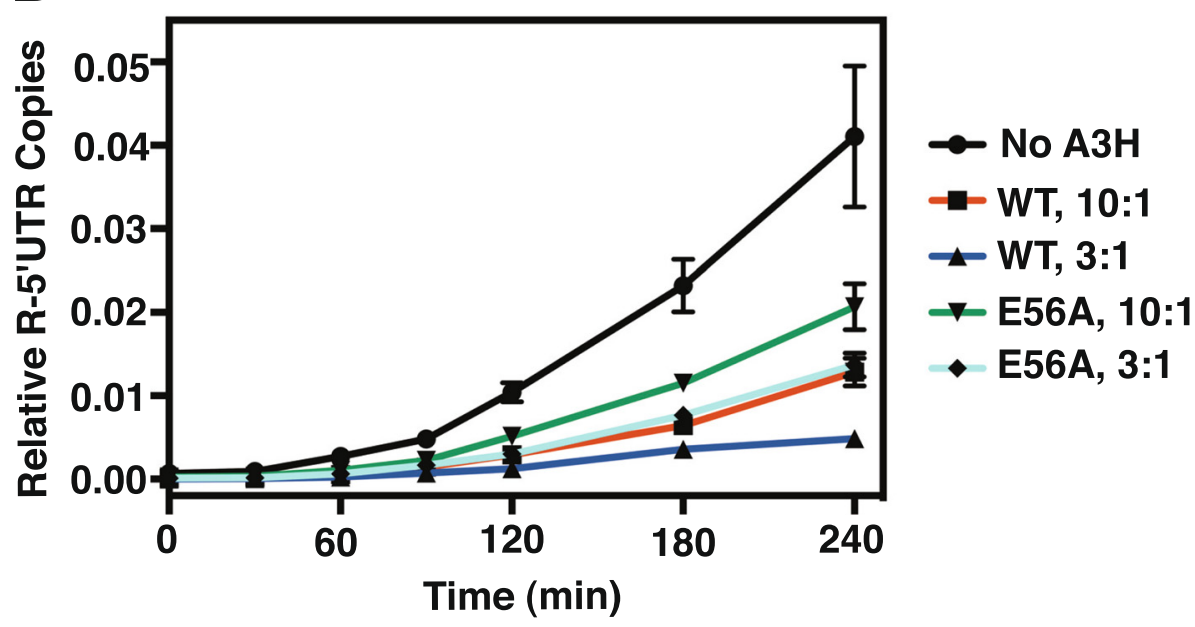

Figure 6 ERT assays of virions produced following transfection of 293T cells with HIV-1vif (-) and WT A3H or the E56A active site mutant. (A and B) Kinetics of DNA synthesis in ERT assays measuring the levels of R-U5 (A) and R-5'UTR (B). The assays were performed as described in Methods. Note that synthesis of R-U5 DNA was more efficient than synthesis of R-5'UTR DNA in the presence of WT A3H under both the 10:1 and 3:1 conditions: the time required for 50\% inhibition was $2 \mathrm{~h}$ for R-U5 and $3 \mathrm{~h}$ for R-5'UTR over the time course of the analysis.

infectivity via deaminase-dependent and -independent mechanisms.

To assess the molecular and structural properties of A3H Hap II, we generated a homology model based on the crystal structure of A3G-CTD (PDB: 3IR2) [53]. The electrostatic surface potential of the $\mathrm{A} 3 \mathrm{H}$ model identified a "large basic patch" (Figure 2B, blue region), containing a cluster of basic residues that could be potentially involved in specific binding to ssDNA substrates as well as binding to cellular RNAs. While this manuscript was under review, a paper by Shandilya et al. [81] appeared, presenting homology models of the individual domains of several $\mathrm{A} 3$ proteins, including $\mathrm{A} 3 \mathrm{H}$. An electrostatic map of this $\mathrm{A} 3 \mathrm{H}$ model also revealed a large basic patch. In fact, comparison of the two structures did not show any significant structural differences.

The basic nature of $\mathrm{A} 3 \mathrm{H}$ is important and impacts catalytic function. Thus, deaminase activity is strongly inhibited upon mutating a subset of the basic residues (R17, R18, R20, R21, Figure 4C; R110, Figure 4F; K168, R171, Figure 4E), suggesting reduced binding to the 40nt nucleic acid substrate. Arginine mutants that were tested also lacked antiviral activity (Figure 5B). However, the basic residues may not all function in the same manner, since the double mutant K168A/R171A retained some deaminase (Figure 4E) as well as restriction activity (Figure 5D). Interestingly, the region corresponding to $\mathrm{R} 17$ to $\mathrm{P} 22$ in $\mathrm{A} 3 \mathrm{H}$ (containing four basic residues) is 
part of an alpha helix (Figure 2), but is not conserved in other A3 domains (Figure 1). In $\mathrm{A} 3 \mathrm{~A}$, this region is completely missing, while in A3C, A3G-CTD, and A3FCTD, there is a loss of four (A3C, A3G-CTD) or two (A3F-CTD) basic residues. Deletion of $\mathrm{A} 3 \mathrm{H}$ residues $\mathrm{R} 20, \mathrm{R} 21$, and P22 (the del(20-22) mutant) results in significant loss, but not complete abolition of deaminase activity (Figure $4 \mathrm{C}$ ), possibly due to perturbation of the local structure in the mutant protein. Although this mutant is efficiently packaged into virions (Figure 5A), it cannot restrict HIV-1 (Figure 5B).

Residues in $\mathrm{A} 3 \mathrm{H}$ that are unique to its $\mathrm{Z} 3$ domain e.g., T81 and V135 are replaced in other active deaminase domains by $\mathrm{S}$ and I respectively, which are chemically similar (Figure 1 and Additional file 1: Figure S1). This implies similarity in function and is consistent with our finding that the $\mathrm{A} 3 \mathrm{H}$ mutants $\mathrm{T} 81 \mathrm{~S}$ and $\mathrm{V} 135 \mathrm{I}$, retain enzymatic (Figure $4 \mathrm{~B}$ and $\mathrm{E}$, respectively) as well as restriction activity (Figure 5C). However, the T81A mutant in which the hydroxyl group common to $\mathrm{T}$ and $\mathrm{S}$, is removed, has only background levels of deaminase activity (Figure 4B). This suggests an important structural role for the hydroxyl group at this position, possibly participation in hydrogen bonding interactions with a nearby side chain. In fact, the $\mathrm{O} \gamma$ atom of S284, the corresponding residue in $\mathrm{A} 3 \mathrm{G}$, is within hydrogen bonding distance to the $\mathrm{Y} 219 \mathrm{H}_{\mathrm{N}}$ backbone atom and is also observed in other A3 proteins $[41,43,49,54]$. It is interesting that despite lacking enzymatic activity, the T81A mutant exhibits significant antiviral activity (Figure 5D).

Although the loop 7 element of A3 proteins plays an essential role in determining deaminase specificity, each protein possesses a unique sequence (Figure 1) and is affected differently when subjected to mutation. For example, as indicated by modeling the A3A/ssDNA complex, the A3A loop 7 cluster of residues (127-ARIYDYDPL-135) interacts with the T (D133) and A (D131, Y132, and D133) nucleotides in the TCA motif, while D131 makes contacts with the central C [41]. Substitutions in all four cluster residues lead to complete loss of A3A deaminase activity [42]. In the case of the A3GCTD loop 7 (313-RIYDDQGR-320), mutation of the only aromatic residue, Y315, negatively impacts deaminase activity [43]. Additionally, changing both D316 and D317 to $\mathrm{R}$ [43] or replacing D317 with the corresponding A3A residue (Y132) [46] results in altered deaminase substrate specificity, as manifested by preferential deamination of the central $\mathrm{C}$ in the motif $\mathrm{CCC}$ instead of the 3' $\mathrm{C}$ (CCC). Exchanging the A3H loop 7 (109-SRLYYHWCK-118) cluster residues YHW with the corresponding A3G-CTD residues, DDQ (YYHW $\rightarrow$ YDDQ), abrogates deamination activity (Figure 4E). This could reflect a change in substrate specificity or in the details of the nucleic acid binding mode due to a protein conformational change. Interestingly, a similar switch in sequence in the case of $\mathrm{A} 3 \mathrm{~A}$ (YDYD $\rightarrow$ YDDD) also reduces activity to background levels [42].

The importance of the A3H W115 residue in loop 7 is underscored by our finding that mutation of W115 to A results in low cellular protein levels (Figures $4 \mathrm{D}$ and $5 \mathrm{~A}$ ), blocks packaging into virions (Figure 5A), and eliminates deaminase (Figure 4F) and antiviral (Figure 5B) activities. Wang et al. [29] were unable to detect expression of (Hap VII) W115A in 293T cells, while Zhen et al. [57] reported that (Hap II) W115A is present at low levels in cell lysates. However, even when expression is equivalent to that of WT (by transfecting cells with a high amount of the Hap II mutant plasmid), W115A is barely detectable in viral lysates, does not restrict HIV-1, and binds cellular RNAs with greatly reduced efficiency [57]. Collectively, these results lend further support to the conclusion that the identity of loop 7 residues is critical for enzyme function.

Surprisingly, although $\mathrm{A} 3 \mathrm{H}$ is highly basic and has only one domain, it more closely resembles the doubledomain proteins $\mathrm{A} 3 \mathrm{D}, \mathrm{A} 3 \mathrm{~F}$, and $\mathrm{A} 3 \mathrm{G}$ than the singledomain $\mathrm{A} 3 \mathrm{~A}$ and $\mathrm{A} 3 \mathrm{C}$ proteins with respect to several important biological properties. For example, like A3D, A3F, and A3G [53,64,82-92], A3H associates in solution in the absence of nucleic acid [93] and forms multimers and high molecular weight ribonucleoprotein complexes in cells [92,94]. In addition, it restricts the infectivity of HIV-1vif (-) virions (Figure 5) [26,27,62,80,94]. The antiHIV-1 activity of A3 proteins A3D, A3F, A3G, and A3H involves (i) packaging of the proteins into the cores of nascent virions in the producer cell $[28,36,95,96]$; and (ii) inhibition of viral replication in the target cell (reviewed in ref. [9]). These parameters are linked to subcellular localization, which varies among the A3 proteins. However, in this case too, just as A3D, A3F, and A3G are located in the cytoplasm [82-84,86,92,97-99], $\mathrm{A} 3 \mathrm{H}$ haplotypes that have antiviral activity (e.g., Hap II) are predominantly cytoplasmic $[28,100]$.

The packaging of antiviral A3 proteins inside the HIV-1 core allows them to interact directly with viral nucleic acids (genomic RNA and nascent DNA synthesized during reverse transcription) in the presence of nucleocapsid protein and reverse transcriptase (RT). Here we show that $\mathrm{A} 3 \mathrm{H}$ inhibits viral infectivity by both deaminasedependent and -independent mechanisms (Figure 5), although it is likely that deaminase-dependent activity is dominant (compare data for WT and the catalytic mutant E56A in Figure 5D, Figure 6, Additional file 4: Figure S4). For A3G, we have proposed a "roadblock" mechanism that is based on its tight nucleic acid binding $[61,101]$ and that is independent of catalytic activity $[69,74]$. We reasoned that since A3G displays slow onoff binding kinetics $[69,79]$, RT is unable to traverse the 
template when A3G is bound and consequently, RTcatalyzed polymerization is blocked. Recent single molecule stretching studies in support of this mechanism showed that A3G can transform from a fast enzyme (required for deamination) to a slow enzyme (causing a roadblock) during the course of protein oligomerization [79].

The highly basic character of the $\mathrm{A} 3 \mathrm{H}$ protein (Figure $2 \mathrm{~B}$, Table 1) (like the NTDs of A3D, A3F, and A3G) strongly suggests that it also binds tightly to viral RNA and DNA, in agreement with studies of A3H binding to cellular RNA [57]. Moreover, the observed reduction in minus- and plus-strand DNA synthesis by RT, even in the absence of deaminase activity (Figure 6) and the fact that $\mathrm{A} 3 \mathrm{H}$ can multimerize $[92,93]$ suggest that a roadblock mechanism might also be relevant to $\mathrm{A} 3 \mathrm{H}$ deaminase-independent HIV-1 restriction (Figure 6). Interestingly, although $\mathrm{A} 3 \mathrm{H}$ mediates hypermutation of HIV-1 [27,48,62] and HBV [17] DNA, the antiviral activity of A3H against HTLV-1 does not involve editing [15].

In summary, $\mathrm{A} 3 \mathrm{H}$ as well as $\mathrm{A} 3 \mathrm{D}, \mathrm{A} 3 \mathrm{~F}$, and $\mathrm{A} 3 \mathrm{G}$ constitute a group of $\mathrm{A} 3$ proteins used by the human innate immune system in its arsenal against HIV-1. The selective pressure to maintain expression of antiviral haplotypes of $\mathrm{A} 3 \mathrm{H}$ in certain populations warrants greater understanding of this protein in terms of its molecular properties. Here, we present such an analysis and correlate enzyme function and antiviral activity. Although $\mathrm{A} 3 \mathrm{H}$ is a single-domain protein and the most divergent member of the A3 family, we show that it utilizes strategies similar to those used by other antiviral doubledomain $\mathrm{A} 3$ proteins (A3D, A3F, and A3G) to counteract HIV-1 infectivity. Knowledge of A3H structure-function relationships should be invaluable for the design of drugs to modulate $\mathrm{A} 3 \mathrm{H}$ deaminase activity and augment its anti-HIV effect. Furthermore, since A3H is a singledomain protein and contains a unique $\mathrm{Z} 3$ domain, it may present a more specific target than the doubledomain antiviral $\mathrm{A} 3$ proteins. Thus, taken together, $\mathrm{A} 3 \mathrm{H}$ clearly provides a molecular paradigm to explore the antiviral response of A3 proteins to retroviral pathogens.

\section{Conclusions}

Based on a homology model of A3H Hap II and the results of extensive mutagenesis, we have identified structural elements and key residues associated with $\mathrm{A} 3 \mathrm{H}$ deaminase and anti-HIV-1 activities. In addition, we provide evidence that $\mathrm{A} 3 \mathrm{H}$ restriction of $\mathrm{HIV}-1$ replication and inhibition of reverse transcription occur by deaminase-dependent and -independent mechanisms.

\section{Methods \\ Materials}

DNA oligonucleotides labeled with AlexaFluor $488^{\circ}$ were obtained from Integrated DNA Technologies (Coralville,
IA). The concentration of each oligonucleotide was determined by measuring its absorbance at $260 \mathrm{~nm}$, using the extinction coefficients provided by the manufacturer. RNase A (endonuclease-free) was purchased from Qiagen Inc. (Germantown, MD). Escherichia coli uracil DNA glycosylase (UDG) was obtained from New England Biolabs (Beverly, MA). Gel loading buffer and nuclease-free water were purchased from Ambion ${ }^{\bullet}$ (Life Technologies, Grand Island, NY). Anti-A3H sera (p3A3 or p1H6), antiHIV-1 CA sera (for ERT experiments), and TZM-bl cells (from John C. Kappes, Xiaoyun Wu, and Tranzyme Inc.) [102-104] were obtained from the AIDS Research and Reference Reagent Program (Division of AIDS, NIAID, NIH). An anti-HIV-1 p24 monoclonal antibody was purchased from ZeptoMetrix (Franklin, MA) and was used for detection of CA and Pr55 $5^{\text {gag }}$ in virions and cell lysates, respectively (see Figure 5). A monoclonal antibody (Anti-FLAG M2) against a FLAG tag was obtained from SigmaAldrich (St. Louis, MO). Anti-tubulin antibody was purchased from Abcam (Cambridge, MA).

\section{Construction of the A3H Hapll homology model}

The initial A3H Hap II homology model was constructed without a $\mathrm{Zn}$ atom and was based on the A3G-CTD crystal structure (PDB: 3IR2) [53] by using MODELLER version 9v8 [56] and the sequence alignment shown in Figure 1 . The $\mathrm{Zn}$ atom was subsequently added to the structure at a position equivalent to that in the structure of A3G-CTD. This was followed by energy minimization where only the $\mathrm{Zn}$ ion and the H54, C85, C88 side-chains were allowed to move. During the energy minimization, the lengths of the coordination bonds were kept as follows: $1.90 \AA$ for the bond between the $\mathrm{Zn}$ ion and the $\mathrm{H} 54 \mathrm{~N}_{\delta 1}$ atom; and $2.25 \AA$ for the bond between the $\mathrm{Zn}$ ion and the C85 or C88 $\mathrm{S}_{\gamma}$ atom. The charge of individual atoms and their radius parameters based on an amber force field [105] were generated by the pdb2pqr program [106]. Partial charges of atoms within the $\mathrm{Zn}$ coordination site were manually adjusted to $+1 \mathrm{e}$ for the $\mathrm{Zn}$ ion, $-0.6 \mathrm{e}$ for the $S_{\gamma}$ atom and +0.1 e for the $C_{\beta}$ atom of the cysteines to account for the approximate redistribution of the charges between the two reduced cysteines and $\mathrm{Zn}$ ion through the coordination bonds. All structure and electrostatic potential map figures were generated with MOLMOL [107]. Sequence identity was determined with DNAStar (http://www.dnastar.com/megalign_help/index. html\#!Documents/calculationofpercent.htm).

\section{Construction of $\mathrm{A} 3 \mathrm{H}$ mutants}

pTR600 mammalian expression plasmids without an insert [108] or containing the A3H HapII coding sequence [27] were a generous gift from Viviana Simon (Mount Sinai School of Medicine, New York, NY) and had either no tag or an $\mathrm{N}$-terminal Flag tag. A3H mutants were all 
constructed in the pTR600 A3H-Flag vector using the QuikChange Lightning Site-Directed Mutagenesis Kit (Agilent Technologies, Santa Clara, CA) or the Tagmaster Site-Directed Mutagenesis Kit (GM Biosciences, Rockville, $\mathrm{MD})$. For primer design, the on-line QuikChange Primer Design Program provided by the manufacturer or the design guidelines provided with the Tagmaster kit were used. Large-scale plasmid preparations were obtained using the HiSpeed Plasmid Maxi Prep kit (Qiagen, Inc.). The A3H sequence in each plasmid was verified by DNA sequencing performed by ACGT (Wheeling, IL).

\section{Preparation of mammalian cell extracts}

Propagation of $293 \mathrm{~T}$ cells, transfection procedure, preparation of cell extracts, and determination of protein concentration were performed as detailed in Mitra et al. [42]. The expression levels of $\mathrm{A} 3 \mathrm{H}$ were estimated by subjecting $\sim 20 \mu \mathrm{g}$ of total protein in the extract to Western blot analysis using the Western Breeze chemiluminescent Western blot kit (Life Technologies). The primary antibodies used for this analysis were anti-A3H or anti-tubulin (loading control).

\section{Deaminase assay}

Prior to performing the deaminase assay, the 293T cell extract $(20 \mu \mathrm{g})$ was treated with RNase A (Qiagen, final concentration $1 \mu \mathrm{g} / \mu \mathrm{l}$ ) in a $20-\mu \mathrm{l}$ reaction volume and incubated at $37^{\circ} \mathrm{C}$ for $15 \mathrm{~min}$, unless indicated otherwise. Details of the deaminase assays and polyacrylamide gel analysis are described in Mitra et al. [42]. A list of oligonucleotides used for the deaminase assays is given in Additional file 5: Table S1. Throughout the text, the $\mathrm{dC}$ residue that is deaminated is highlighted in bold (C). A 40-nt Alexa-Fluor 488-labeled ssDNA (JL913) containing the TTCA deaminase motif was used as the substrate, unless specified otherwise. To calculate the percent deaminase product, the product signal intensity for each lane was divided by total signal intensity and multiplied by 100 . The data presented represent the average of two determinations from two independent transfections. Note that the FLAG tag did not interfere with deaminase activity, as untagged and tagged WT A3H showed similar levels of activity (Figure 4C).

\section{HIV-1 infectivity assay}

To assay the effect of expressing A3H WT or mutant proteins on HIV-1 infectivity, 293T cells were cotransfected with $1.0 \mu$ g of pNL4-3vif (-), which was kindly provided by Klaus Strebel (National Institute of Allergy and Infectious Diseases, National Institutes of Health, Bethesda, MD) and 1.0 or $0.1 \mu \mathrm{g}$ of the pTR600 A3H HapII plasmid (WT or mutant) or pTR600 empty vector (control), using the FuGENE HD transfection agent (Promega, Madison, WI) as previously described [49]. Virus-containing supernatants were collected $48 \mathrm{~h}$ after transfection and filtered. The amount of CA protein (i.e., p24 antigen) in the supernatant was determined by ELISA assay (ZeptoMetrix, Buffalo, NY). TZM-bl indicator cells were infected with viral supernatant containing $10 \mathrm{ng}$ of CA. Relative infectivity expressed as relative light units (RLU) was measured using the Bright-Glo luciferase assay system kit (Promega) and an ARVO MX luminescence counter (PerkinElmer, Waltham, MA). The data represent the results of three independent experiments.

\section{ERT assay}

The following plasmids were used: pTR600, empty vector; WT A3H HapII expressed as an N-terminal FLAG-tagged protein in pTR600 (pA3H WT); A3H E56A active site mutant expressed as an N-terminal FLAG-tagged protein in pTR600 (pA3H E56A); and pNL4-3vif (-).

Transfections were performed as described previously [109], except that TransIT-293 from Mirus Bio LLC (Madison, WI) was used, according to the manufacturer's instructions. Briefly, 100-mm cell culture dishes were seeded with $3 \times 10^{5} 293 \mathrm{~T}$ cells in Dulbecco's modified Eagle's Medium with 10\% fetal bovine serum. Two days later, the cells were transfected in duplicate with $15 \mu \mathrm{g}$ of pNL4-3vif (-) and $0,1.5$, or $5 \mu \mathrm{g}$ of pA3H WT or pA3H E56A plasmid; the molar ratios of pNL4-3vif $(-)$ to $\mathrm{A} 3 \mathrm{H}$ plasmid were therefore $10: 1$ or $3: 1$, respectively. The pTR600 plasmid was the negative control and was also used to generate a constant level $(5 \mu \mathrm{g})$ of transfected pTR600 DNA, with or without the A3H insert. Culture fluids were changed $24 \mathrm{~h}$ after transfection, then harvested after two consecutive 24-h periods, and passed through $0.22 \mu \mathrm{m}$ filters. Samples from each culture were pooled and were treated sequentially with DNase I and subtilisin, as described $[109,110]$.

ERT reactions were performed without Triton X-100 pretreatment and nucleic acids were isolated as detailed in Thomas et al. [109]. Real-time PCR for the detection of R-U5 and R-5'UTR was performed in duplicate as described previously [111]. The kinetics of DNA synthesis were plotted and the data were normalized relative to maximal R-U5 copies at 240 min for pNL4-3vif (-) in the absence of $\mathrm{A} 3 \mathrm{H}$ cotransfected plasmid. Each data point was the result of two independent transfections, each measured in duplicate. Error bars represent the standard error of the mean.

\section{Additional files}

Additional file 1: Figure S1. Sequence alignment of residues in the Zn-binding ( $\mathrm{Z}$ ) domains of the seven $\mathrm{A} 3$ proteins ( $\mathrm{A}$ to $\mathrm{H}$ ). The $\mathrm{Zn}$-coordinating ( $\mathrm{H}$ and $\mathrm{C}$ ) and active site (E) residues are highlighted in light blue. $\mathrm{A} 3 \mathrm{H}$ residues that differ from highly conserved residues at the corresponding positions in the other A3 proteins are shown in lavender. 
The residues in loop 7 are bracketed. The numbers at the end of each line represent the position in the full-length protein. The percent sequence identity of each $\mathrm{Z}$ domain relative to that of $\mathrm{A} 3 \mathrm{H}$ (defined as $100 \%$ ) is indicated. The sequence alignment was performed using Lasergene software (DNASTAR, Inc., Madison, WI).

Additional file 2: Figure S2. Superposition of the structures of the current $\mathrm{A} 3 \mathrm{H}$ model and other $\mathrm{A} 3$ proteins in ribbon representation. The backbone traces are colored gray $(\mathrm{A} 3 \mathrm{H})$ and green (other $\mathrm{A} 3$ proteins). The $\mathrm{Zn}$ ions are shown in brown ( $\mathrm{A} 3 \mathrm{H})$ and in coral (other $\mathrm{A} 3$ proteins). (A) $\mathrm{A} 3 \mathrm{H}$ and $\mathrm{A} 3 \mathrm{G}-\mathrm{CTD}$. (B) $\mathrm{A} 3 \mathrm{H}$ and $\mathrm{A} 3 \mathrm{~A}$. (C) $\mathrm{A} 3 \mathrm{H}$ and $\mathrm{A} 3 \mathrm{C}$. (D) $\mathrm{A} 3 \mathrm{H}$ and A3F-CTD.

Additional file 3: Figure S3. Electrostatic surface potential maps of $\mathrm{A} 3 \mathrm{H}$ and other $\mathrm{A} 3$ proteins. (A) A3H. (B) A3G-CTD. (C) A3A. (D) A3C. (E) A3F-CTD. Regions with positive and negative electrostatic potentials are highlighted in blue and red, respectively.

Additional file 4: Figure S4. Comparison of antiviral activities of $\mathrm{A3H}$ and A3G WT and catalytic mutants. Virions produced from 293T cells transfected with HIV-1vif(-) $(1 \mu \mathrm{g})$ and either 0.1 (gray bars) or $1 \mu \mathrm{g}$ (black bars) of the indicated A3H or A3G WT or mutant plasmids. Infectivity was assayed as described in Methods. The catalytic mutants are E56A (A3H) and E259Q (A3G). A vector control (100\% infectivity) was also included.

Additional file 5: Table S1. Oligonucleotides used for deaminase assays.

\section{Abbreviations}

A3: APOBEC3; ss: Single-stranded; HIV-1: Human immunodeficiency virus type 1; HTLV-1: Human T-lymphotropic virus type 1; HBV: Hepatitis B virus; CTD: C-terminal domain; NTD: N-terminal domain; WT: Wild type; ERT: Endogenous reverse transcription; CA: Capsid protein; RT: Reverse transcriptase.

\section{Competing interests}

The authors declare that they have no competing interests.

\section{Authors' contributions}

The study was conceived by MM and JGL. MM, DS, YM, GN, RJG, and $\mathrm{YI}$ performed experiments. MM, RJG, YI, and JGL analyzed the experimental data. $\mathrm{JH}$ built the structural model of $\mathrm{A} 3 \mathrm{H}$ and $\mathrm{MM}$ and $J \mathrm{H}$ designed the mutants. I-JLB made the structural figures and I-JLB and $J H$ interpreted the electrostatic surface potential maps. I-JLB, MM, and AMG interpreted the structure-related mutagenesis data. MM, I-JLB, YI, AMG, and JGL wrote the paper. All authors read and approved the final manuscript.

\section{Acknowledgements}

We thank Dr. Viviana Simon and Dr. Marcel Ooms for their generous gift of the WT A3H and empty pTR600 plasmids, Dr. Klaus Strebel for kindly providing the pNL4-3vif(-) plasmid used in the ERT assays, Drs. Simon, Ooms, and Tiyun Wu for valuable discussion, and the AIDS Research and Reference Reagent Program, Division of AIDS, NIAID, NIH for antisera and cells, as detailed in the text. J.H. acknowledges financial support by an International Outgoing Fellowship of the European Community program "Support for training and career development of researchers (Marie Curie)", under Contract No. PIOF-GA-2009-235902. This work was supported in part by the Intramural Research Program at the National Institutes of Health, Eunice Kennedy Shriver National Institute of Child Health and Human Development (MM, DS, GN, and JGL), National Institutes of Health grant P50GM82251 $(J H, I-J L B$, and $A M G)$, and a grant-in-aid for Scientific Research from the Ministry of Education, Culture, Sports, Science, and Technology of Japan (YM and $\mathrm{Yl})$. This project has also been funded in whole or in part with federal funds from the National Cancer Institute, National Institutes of Health, under contract HHSN261200800001E with Leidos Biomedical Research, Inc. The content of this publication does not necessarily reflect the views or policies of the Department of Health and Human Services, nor does mention of trade names, commercial products, or organizations imply endorsement by the U.S. Government (RJG).

\section{Author details}

'Section on Viral Gene Regulation, Program in Genomics of Differentiation, Eunice Kennedy Shriver National Institute of Child Health and Human Development, National Institutes of Health, Bethesda, MD 20892-2780, USA. ${ }^{2}$ Clinical Research Center, National Hospital Organization Nagoya Medical Center, Nagoya, Aichi 460-0001, Japan. ${ }^{3}$ Department of Structural Biology, University of Pittsburgh Medical School, Pittsburgh, PA 15261, USA. ${ }^{4}$ Pittsburgh Center for HIV Protein Interactions, University of Pittsburgh Medical School, Pittsburgh, PA 15261, USA. ${ }^{5}$ AIDS and Cancer Virus Program, Leidos Biomedical Research, Inc., Frederick National Laboratory for Cancer Research, Frederick, MD 21702-1201, USA. 'Department of Molecular, Cell and Developmental Biology, University of California, Los Angeles, CA 90095, USA. ${ }^{7}$ Department of Structural Biology, CEITEC, Masaryk University, Kamenice 5, 62500 Brno, Czech Republic.

Received: 14 October 2014 Accepted: 17 December 2014 Published online: 22 January 2015

\section{References}

1. Sheehy AM, Gaddis NC, Choi JD, Malim MH. Isolation of a human gene that inhibits HIV-1 infection and is suppressed by the viral Vif protein. Nature. 2002;418:646-50.

2. Lecossier D, Bouchonnet F, Clavel F, Hance AJ. Hypermutation of HIV-1 DNA in the absence of the Vif protein. Science. 2003;300:1112.

3. Zhang H, Yang B, Pomerantz RJ, Zhang C, Arunachalam SC, Gao L. The cytidine deaminase CEM15 induces hypermutation in newly synthesized HIV-1 DNA. Nature. 2003;424:94-8.

4. Suspène $R$, Sommer $P$, Henry $M$, Ferris $S$, Guétard D, Pochet $S$, et al. APOBEC $3 G$ is a single-stranded DNA cytidine deaminase and functions independently of HIV reverse transcriptase. Nucleic Acids Res. 2004;32:2421-9.

5. Yu Q, König R, Pillai S, Chiles K, Kearney M, Palmer S, et al. Single-strand specificity of APOBEC3G accounts for minus-strand deamination of the HIV genome. Nat Struct Mol Biol. 2004;11:435-42.

6. Harris RS, Liddament MT. Retroviral restriction by APOBEC proteins. Nat Rev Immunol. 2004;4:868-77.

7. Chiu YL, Greene WC. The APOBEC3 cytidine deaminases: an innate defensive network opposing exogenous retroviruses and endogenous retroelements. Annu Rev Immunol. 2008;26:317-53.

8. Goila-Gaur R, Strebel K. HIV-1 Vif, APOBEC, and intrinsic immunity. Retrovirology. 2008;5:51.

9. Malim MH. APOBEC proteins and intrinsic resistance to HIV-1 infection. Philos Trans R Soc Lond B Biol Sci. 2009;364:675-87.

10. Imahashi M, Nakashima M, Iwatani Y. Antiviral mechanism and biochemical basis of the human APOBEC3 family. Front Microbiol. 2012;3:250.

11. Duggal NK, Fu W, Akey JM, Emerman M. Identification and antiviral activity of common polymorphisms in the APOBEC3 locus in human populations. Virology. 2013;443:329-37.

12. Desimmie BA, Delviks-Frankenberrry KA, Burdick RC, Qi D, Izumi T, Pathak VK. Multiple APOBEC3 restriction factors for HIV-1 and one Vif to rule them all. J Mol Biol. 2014;426:1220-45.

13. Feng Y, Baig TT, Love RP, Chelico L. Suppression of APOBEC3-mediated restriction of HIV-1 by Vif. Front Microbiol. 2014;5:450.

14. Sasada A, Takaori-Kondo A, Shirakawa K, Kobayashi M, Abudu A, Hishizawa M, et al. APOBEC3G targets human T-cell leukemia virus type 1. Retrovirology. 2005;2:32.

15. Ooms M, Krikoni A, Kress AK, Simon V, Münk C. APOBEC3A, APOBEC3B, and APOBEC3H haplotype 2 restrict human T-lymphotropic virus type 1. J Virol. 2012;86:6097-108.

16. Turelli $P$, Mangeat $B$, Jost $S$, Vianin S, Trono D. Inhibition of hepatitis B virus replication by APOBEC3G. Science. 2004;303:1829.

17. Köck J, Blum HE. Hypermutation of hepatitis B virus genomes by APOBEC3G, APOBEC3C and APOBEC3H. J Gen Virol. 2008;89:1184-91.

18. Koito A, Ikeda T. Intrinsic immunity against retrotransposons by APOBEC cytidine deaminases. Front Microbiol. 2013;4:28.

19. Jarmuz A, Chester A, Bayliss J, Gisbourne J, Dunham I, Scott J, et al. An anthropoid-specific locus of orphan C to U RNA-editing enzymes on chromosome 22. Genomics. 2002;79:285-96.

20. Holmes RK, Malim MH, Bishop KN. APOBEC-mediated viral restriction: not simply editing? Trends Biochem Sci. 2007;32:118-28.

21. Bransteitter R, Prochnow C, Chen XS. The current structural and functional understanding of APOBEC deaminases. Cell Mol Life Sci. 2009;66:3137-47. 
22. Betts L, Xiang S, Short SA, Wolfenden R, Carter Jr CW. Cytidine deaminase. The $2.3 \AA$ crystal structure of an enzyme: transition-state analog complex. J Mol Biol. 1994;235:635-56.

23. LaRue RS, Jónsson SR, Silverstein KAT, Lajoie M, Bertrand D, El-Mabrouk N, et al. The artiodactyl APOBEC3 innate immune repertoire shows evidence for a multi-functional domain organization that existed in the ancestor of placental mammals. BMC Mol Biol. 2008;9:104.

24. LaRue RS, Andrésdóttir $V$, Blanchard Y, Conticello SG, Derse D, Emerman M, et al. Guidelines for naming nonprimate APOBEC3 genes and proteins. J Virol. 2009:83:494-7.

25. OhAinle M, Kerns JA, Malik HS, Emerman M. Adaptive evolution and antiviral activity of the conserved mammalian cytidine deaminase APOBEC $3 \mathrm{H}$. J Virol. 2006;80:3853-62.

26. OhAinle M, Kerns JA, Li MMH, Malik HS, Emerman M. Antiretroelement activity of APOBEC3H was lost twice in recent human evolution. Cell Host Microbe. 2008:4:249-59.

27. Harari A, Ooms M, Mulder LCF, Simon V. Polymorphisms and splice variants influence the antiretroviral activity of human APOBEC3H. J Virol. 2009:83:295-303

28. Ooms M, Majdak S, Seibert CW, Harari A, Simon V. The localization of APOBEC3H variants in HIV-1 virions determines their antiviral activity. J Virol. 2010;84:7961-9.

29. Wang X, Abudu A, SungMo S, Dang Y, Venta PJ, Zheng Y-H. Analysis of human APOBEC3H haplotypes and anti-human immunodeficiency virus type 1 activity. J Virol. 2011;85:3142-52.

30. Li MMH, Wu LI, Emerman M. The range of human APOBEC3H sensitivity to lentiviral Vif proteins. J Virol. 2010;84:88-95.

31. Zhen A, Wang T, Zhao K, Xiong Y, Yu X-F. A single amino acid difference in human APOBEC3H variants determines HIV-1 Vif sensitivity. J Virol. 2010;84:1902-11.

32. Ooms M, Brayton B, Letko M, Maio SM, Pilcher CD, Hecht FM, et al. HIV-1 Vif adaptation to human APOBEC3H haplotypes. Cell Host Microbe. 2013;14:411-21.

33. Binka M, Ooms M, Steward M, Simon V. The activity spectrum of Vif from multiple HIV-1 subtypes against APOBEC3G, APOBEC3F, and APOBEC3H. J Virol. 2012;86:49-59.

34. Ooms $M$, Letko $M$, Binka $M$, Simon $V$. The resistance of human APOBEC3H to HIV-1 NL4-3 molecular clone is determined by a single amino acid in Vif. PLoS One. 2013;8:e57744.

35. Chen H, Lilley CE, Yu Q, Lee DV, Chou J, Narvaiza I, et al. APOBEC3A is a potent inhibitor of adeno-associated virus and retrotransposons. Curr Biol. 2006:16:480-5.

36. Aguiar RS, Lovsin N, Tanuri A, Peterlin BM. Vpr.A3A chimera inhibits HIV replication. J Biol Chem. 2008;283:2518-25.

37. Stenglein MD, Burns MB, Li M, Lengyel J, Harris RS. APOBEC3 proteins mediate the clearance of foreign DNA from human cells. Nat Struct Mol Biol. 2010;17:222-9.

38. Bulliard Y, Narvaiza I, Bertero A, Peddi S, Röhrig UF, Ortiz M, et al. Structurefunction analyses point to a polynucleotide-accommodating groove essential for APOBEC3A restriction activities. J Virol. 2011;85:1765-76.

39. Love RP, $\mathrm{Xu} \mathrm{H}$, Chelico L. Biochemical analysis of hypermutation by the deoxycytidine deaminase APOBEC3A. J Biol Chem. 2012;287:30812-22.

40. Shinohara M, lo K, Shindo K, Matsui M, Sakamoto T, Tada K, et al. APOBEC3B can impair genomic stability by inducing base substitutions in genomic DNA in human cells. Sci Rep. 2012;2:806.

41. Byeon I-JL, Ahn J, Mitra M, Byeon C-H, Hercík K, Hritz J, et al. NMR structure of human restriction factor $\mathrm{APOBEC}$ A reveals substrate binding and enzyme specificity. Nat Commun. 2013;4:1890.

42. Mitra M, Hercík K, Byeon I-JL, Ahn J, Hill S, Hinchee-Rodriguez K, et al. Structural determinants of human APOBEC3A enzymatic and nucleic acid binding properties. Nucleic Acids Res. 2014;42:1095-110.

43. Holden LG, Prochnow C, Chang YP, Bransteitter R, Chelico L, Sen U, et al. Crystal structure of the anti-viral APOBEC3G catalytic domain and functional implications. Nature. 2008;456:121-4.

44. Carpenter MA, Rajagurubandara E, Wijesinghe P, Bhagwat AS. Determinants of sequence-specificity within human AID and APOBEC3G. DNA Repair. 2010;9:579-87.

45. Kohli RM, Maul RW, Guminski AF, McClure RL, Gajula KS, Saribasak H, et al. Local sequence targeting in the AID/APOBEC family differentially impacts retroviral restriction and antibody diversification. J Biol Chem. 2010;285:40956-64.
46. Rathore A, Carpenter MA, Demir Ö, Ikeda T, Li M, Shaban NM, et al. The local dinucleotide preference of APOBEC3G can be altered from 5'-CC to 5'-TC by a single amino acid substitution. J Mol Biol. 2013;425:4442-54.

47. Aydin H, Taylor MW, Lee JE. Structure-guided analysis of the human APOBEC3-HIV restrictome. Structure. 2014;22:668-84.

48. Kim E-Y, Lorenzo-Redondo R, Little SJ, Chung Y-S, Phalora PK, Maljkovic Berry I, et al. Human APOBEC3 induced mutation of human immunodeficiency virus type-1 contributes to adaptation and evolution in natural infection. PLoS Pathog. 2014;10:e1004281.

49. Kitamura S, Ode H, Nakashima M, Imahashi M, Naganawa Y, Kurosawa T, et al. The APOBEC3C crystal structure and the interface for HIV-1 Vif binding. Nat Struct Mol Biol. 2012;19:1005-10.

50. Chen KM, Harjes E, Gross PJ, Fahmy A, Lu Y, Shindo K, et al. Structure of the DNA deaminase domain of the HIV-1 restriction factor APOBEC3G. Nature. 2008;452:116-9.

51. Furukawa A, Nagata T, Matsugami A, Habu Y, Sugiyama R, Hayashi F, et al. Structure, interaction and real-time monitoring of the enzymatic reaction of wild-type APOBEC3G. EMBO J. 2009;28:440-51.

52. Harjes E, Gross PJ, Chen K-M, Lu Y, Shindo K, Nowarski R, et al. An extended structure of the APOBEC3G catalytic domain suggests a unique holoenzyme model. J Mol Biol. 2009;389:819-32.

53. Shandilya SMD, Nalam MNL, Nalivaika EA, Gross PJ, Valesano JC, Shindo K, et al. Crystal structure of the APOBEC3G catalytic domain reveals potential oligomerization interfaces. Structure. 2010;18:28-38.

54. Bohn M-F, Shandilya SMD, Albin JS, Kouno T, Anderson BD, McDougle RM, et al. Crystal structure of the DNA cytosine deaminase APOBEC3F: the catalytically active and HIV-1 Vif-binding domain. Structure. 2013;21:1042-50.

55. Siu KK, Sultana A, Azimi FC, Lee JE. Structural determinants of HIV-1 Vif susceptibility and DNA binding in APOBEC3F. Nat Commun. 2013:4:2593.

56. Šali A, Blundell TL. Comparative protein modelling by satisfaction of spatial restraints. J Mol Biol. 1993;234:779-815.

57. Zhen A, Du J, Zhou X, Xiong Y, Yu X-F. Reduced APOBEC3H variant anti-viral activities are associated with altered RNA binding activities. PLoS One. 2012;7:e38771.

58. Haché G, Liddament MT, Harris RS. The retroviral hypermutation specificity of APOBEC3F and APOBEC3G is governed by the C-terminal DNA cytosine deaminase domain. J Biol Chem. 2005;280:10920-4.

59. Langlois M-A, Beale RCL, Conticello SG, Neuberger MS. Mutational comparison of the single-domained $\mathrm{APOBEC} 3 \mathrm{C}$ and double-domained APOBEC3F/G anti-retroviral cytidine deaminases provides insight into their DNA target site specificities. Nucleic Acids Res. 2005;33:1913-23.

60. Navarro F, Bollman B, Chen H, König R, Yu Q, Chiles K, et al. Complementary function of the two catalytic domains of APOBEC3G. Virology. 2005;333:374-86.

61. Iwatani Y, Takeuchi H, Strebel K, Levin JG. Biochemical activities of highly purified, catalytically active human APOBEC3G: correlation with antiviral effect. J Virol. 2006;80:5992-6002.

62. Hultquist JF, Lengyel JA, Refsland EW, LaRue RS, Lackey L, Brown WL, et al. Human and rhesus APOBEC3D, APOBEC 3F, APOBEC3G, and APOBEC3H demonstrate a conserved capacity to restrict Vif-deficient HIV-1. J Virol. 2011;85:11220-34.

63. McDougall WM, Smith HC. Direct evidence that RNA inhibits APOBEC3G ssDNA cytidine deaminase activity. Biochem Biophys Res Commun. 2011:412:612-7.

64. Huthoff $\mathrm{H}$, Autore F, Gallois-Montbrun S, Fraternali F, Malim MH. RNA-dependent oligomerization of APOBEC3G is required for restriction of HIV-1. PLoS Pathog. 2009;5:e1000330.

65. Newman ENC, Holmes RK, Craig HM, Klein KC, Lingappa JR, Malim MH, et al. Antiviral function of APOBEC3G can be dissociated from cytidine deaminase activity. Curr Biol. 2005;15:166-70.

66. Bishop KN, Holmes RK, Malim MH. Antiviral potency of APOBEC proteins does not correlate with cytidine deamination. J Virol. 2006;80:8450-8.

67. Guo F, Cen S, Niu M, Saadatmand J, Kleiman L. Inhibition of tRNA ${ }_{3}^{\text {Lys }}{ }_{\text {- }}$ primed reverse transcription by human APOBEC3G during human immunodeficiency virus type 1 replication. J Virol. 2006;80:11710-22.

68. Holmes RK, Koning FA, Bishop KN, Malim MH. APOBEC3F can inhibit the accumulation of HIV-1 reverse transcription products in the absence of hypermutation. Comparisons with APOBEC3G. J Biol Chem. 2007;282:2587-95.

69. Iwatani Y, Chan DSB, Wang F, Maynard KS, Sugiura W, Gronenborn AM, et al. Deaminase-independent inhibition of HIV-1 reverse transcription by APOBEC3G. Nucleic Acids Res. 2007;35:7096-108. 
70. Li X-Y, Guo F, Zhang L, Kleiman L, Cen S. APOBEC3G inhibits DNA strand transfer during HIV-1 reverse transcription. J Biol Chem. 2007;282:32065-74.

71. Luo K, Wang T, Liu B, Tian C, Xiao Z, Kappes J, et al. Cytidine deaminases APOBEC3G and APOBEC3F interact with human immunodeficiency virus type 1 integrase and inhibit proviral DNA formation. J Virol. 2007:81:7238-48.

72. Mbisa JL, Barr R, Thomas JA, Vandegraaff N, Dorweiler IJ, Svarovskaia ES, et al. Human immunodeficiency virus type 1 cDNAs produced in the presence of APOBEC3G exhibit defects in plus-strand DNA transfer and integration. J Virol. 2007:81:7099-110.

73. Bishop KN, Verma M, Kim E-Y, Wolinsky SM, Malim MH. APOBEC3G inhibits elongation of HIV-1 reverse transcripts. PLoS Pathog. 2008;4:e1000231.

74. Levin JG, Mitra M, Mascarenhas A, Musier-Forsyth K. Role of HIV-1 nucleocapsid protein in HIV-1 reverse transcription. RNA Biol. 2010;7:754-74.

75. Wang X, Ao Z, Chen L, Kobinger G, Peng J, Yao X. The cellular antiviral protein $A P O B E C 3 G$ interacts with HIV-1 reverse transcriptase and inhibits its function during viral replication. J Virol. 2012;86:3777-86.

76. Adolph MB, Webb J, Chelico L. Retroviral restriction factor APOBEC3G delays the initiation of DNA synthesis by HIV-1 reverse transcriptase. PLoS One. 2013;8:e64196.

77. Bélanger K, Savoie M, Rosales Gerpe MC, Couture J-F, Langlois M-A. Binding of RNA by APOBEC3G controls deamination-independent restriction of retroviruses. Nucleic Acids Res. 2013;41:7438-52.

78. Gillick K, Pollpeter D, Phalora P, Kim E-Y, Wolinsky SM, Malim MH. Suppression of HIV-1 infection by APOBEC3 proteins in primary human $\mathrm{CD}^{+} \mathrm{T}$ cells is associated with inhibition of processive reverse transcription as well as excessive cytidine deamination. J Virol. 2013;87:1508-17.

79. Chaurasiya KR, McCauley MJ, Wang W, Qualley DF, Wu T, Kitamura S, et al. Oligomerization transforms human APOBEC3G from an efficient enzyme to a slowly dissociating nucleic acid-binding protein. Nat Chem. 2014;6:28-33.

80. Dang $Y$, Siew LM, Wang $X$, Han Y, Lampen R, Zheng YH. Human cytidine deaminase APOBEC3H restricts HIV-1 replication. J Biol Chem. 2008;283:11606-14.

81. Shandilya SMD, Bohn M-F, Schiffer CA. A computational analysis of the structural determinants of APOBEC3's catalytic activity and vulnerability to HIV-1 Vif. Virology. 2014:471-473:105-16.

82. Chiu Y-L, Witkowska HE, Hall SC, Santiago M, Soros VB, Esnault C, et al. High-molecular-mass APOBEC3G complexes restrict Alu retrotransposition. Proc Natl Acad Sci U S A. 2006;103:15588-93.

83. Kozak SL, Marin M, Rose KM, Bystrom C, Kabat D. The anti-HIV-1 editing enzyme APOBEC3G binds HIV-1 RNA and messenger RNAs that shuttle between polysomes and stress granules. J Biol Chem. 2006;281:29105-19.

84. Gallois-Montbrun S, Kramer B, Swanson CM, Byers H, Lynham S, Ward M, et al. Antiviral protein APOBEC3G localizes to ribonucleoprotein complexes found in P bodies and stress granules. J Virol. 2007;81:2165-78.

85. Chelico L, Sacho EJ, Erie DA, Goodman MF. A model for oligomeric regulation of $A P O B E C 3 G$ cytosine deaminase-dependent restriction of HIV. J Biol Chem. 2008;283:13780-91.

86. Gallois-Montbrun S, Holmes RK, Swanson CM, Fernández-Ocaña M, Byers HL, Ward MA, et al. Comparison of cellular ribonucleoprotein complexes associated with the APOBEC3F and APOBEC3G antiviral proteins. J Virol. 2008;82:5636-42.

87. Friew YN, Boyko V, Hu W-S, Pathak VK. Intracellular interactions between APOBEC3G, RNA, and HIV-1 Gag: APOBEC3G multimerization is dependent on its association with RNA. Retrovirology. 2009;6:56.

88. Salter JD, Krucinska J, Raina J, Smith HC, Wedekind JE. A hydrodynamic analysis of APOBEC3G reveals a monomer-dimer-tetramer self-association that has implications for anti-HIV function. Biochemistry. 2009;48:10685-7.

89. Chelico L, Prochnow C, Erie DA, Chen XS, Goodman MF. Structural model for deoxycytidine deamination mechanisms of the HIV-1 inactivation enzyme APOBEC3G. J Biol Chem. 2010;285:16195-205.

90. McDougall WM, Okany C, Smith HC. Deaminase activity on single-stranded DNA (ssDNA) occurs in vitro when APOBEC3G cytidine deaminase forms homotetramers and higher-order complexes. J Biol Chem. 2011;286:30655-61.

91. Shlyakhtenko LS, Lushnikov AY, Li M, Lackey L, Harris RS, Lyubchenko YL. Atomic force microscopy studies provide direct evidence for dimerization of the HIV restriction factor APOBEC3G. J Biol Chem. 2011;286:3387-95.

92. Li J, Chen Y, Li M, Carpenter MA, McDougle RM, Luengas EM, et al. APOBEC3 multimerization correlates with HIV-1 packaging and restriction activity in living cells. J Mol Biol. 2014;426:1296-307.
93. Baig $\Pi$, Feng $Y$, Chelico L. Determinants of efficient degradation of APOBEC3 restriction factors by HIV-1 Vif. J Virol. 2014;88:14380-95.

94. Tan L, Sarkis PTN, Wang T, Tian C, Yu X-F. Sole copy of Z2-type human cytidine deaminase APOBEC3H has inhibitory activity against retrotransposons and HIV-1. FASEB J. 2009;23:279-87.

95. Goila-Gaur R, Khan MA, Miyagi E, Kao S, Strebel K. Targeting APOBEC3A to the viral nucleoprotein complex confers antiviral activity. Retrovirology. 2007:4:61.

96. Song C, Sutton L, Johnson ME, D'Aquila RT, Donahue JP. Signals in APOBEC3F N-terminal and C-terminal deaminase domains each contribute to encapsidation in HIV-1 virions and are both required for HIV-1 restriction. J Biol Chem. 2012;287:16965-74.

97. Bennett RP, Diner E, Sowden MP, Lees JA, Wedekind JE, Smith HC APOBEC-1 and AID are nucleo-cytoplasmic trafficking proteins but APOBEC3G cannot traffic. Biochem Biophys Res Commun. 2006:350:214-9.

98. Wichroski MJ, Robb GB, Rana TM. Human retroviral host restriction factors APOBEC3G and APOBEC3F localize to mRNA processing bodies. PLoS Pathog. 2006;2:e41.

99. Bennett RP, Presnyak V, Wedekind JE, Smith HC. Nuclear exclusion of the HIV-1 host defense factor APOBEC3G requires a novel cytoplasmic retention signal and is not dependent on RNA binding. J Biol Chem. 2008;283:7320-7.

100. Li MMH, Emerman M. Polymorphism in human APOBEC3H affects a phenotype dominant for subcellular localization and antiviral activity. J Virol. 2011;85:8197-207.

101. Chelico L, Pham P, Calabrese P, Goodman MF. APOBEC3G DNA deaminase acts processively $3^{\prime} \rightarrow 5^{\prime}$ on single-stranded DNA. Nat Struct Mol Biol. 2006;13:392-9.

102. Platt EJ, Wehrly K, Kuhmann SE, Chesebro B, Kabat D. Effects of CCR5 and CD4 cell surface concentrations on infections by macrophagetropic isolates of human immunodeficiency virus type 1. J Virol. 1998;72:2855-64.

103. Derdeyn CA, Decker JM, Sfakianos JN, Wu X, O'Brien WA, Ratner L, et al. Sensitivity of human immunodeficiency virus type 1 to the fusion inhibitor T-20 is modulated by coreceptor specificity defined by the V3 loop of gp120. J Virol. 2000;74:8358-67.

104. Wei X, Decker JM, Liu H, Zhang Z, Arani RB, Kilby JM, et al. Emergence of resistant human immunodeficiency virus type 1 in patients receiving fusion inhibitor (T-20) monotherapy. Antimicrob Agents Chemother. 2002;46:1896-905.

105. Wang J, Wolf RM, Caldwell JW, Kollman PA, Case DA. Development and testing of a general amber force field. J Comput Chem. 2004;25:1157-74.

106. Dolinsky TJ, Czodrowski P, Li H, Nielsen JE, Jensen JH, Klebe G, et al. PDB2PQR: expanding and upgrading automated preparation of biomolecular structures for molecular simulations. Nucleic Acids Res. 2007;35:W522-5.

107. Koradi R, Billeter M, Wüthrich K. MOLMOL: a program for display and analysis of macromolecular structures. J Mol Graph. 1996;14:51-5.

108. Green TD, Newton BR, Rota PA, Xu Y, Robinson HL, Ross TM. C3d enhancement of neutralizing antibodies to measles hemagglutinin. Vaccine. 2001;20:242-8

109. Thomas JA, Shatzer TL, Gorelick RJ. Blocking premature reverse transcription fails to rescue the HIV-1 nucleocapsid-mutant replication defect. Retrovirology. 2011;8:46.

110. Ott DE, Coren LV, Johnson DG, Sowder II RC, Arthur LO, Henderson LE. Analysis and localization of cyclophilin $A$ found in the virions of human immunodeficiency virus type 1 MN strain. AIDS Res Hum Retroviruses. 1995;11:1003-6.

111. Thomas JA, Gagliardi TD, Alvord WG, Lubomirski M, Bosche WJ, Gorelick RJ. Human immunodeficiency virus type 1 nucleocapsid zinc-finger mutations cause defects in reverse transcription and integration. Virology. 2006;353:41-51. 